\title{
Ganglioside Detection from Formalin Fixed Human Brain Tissue Utilizing MALDI Imaging Mass Spectrometry
}

Aaron Harris, The University of Western Ontario

Supervisor: Yeung, Ken, The University of Western Ontario

Co-Supervisor: Whitehead, Shawn, The University of Western Ontario

A thesis submitted in partial fulfillment of the requirements for the Master of Science degree in Chemistry

(C) Aaron Harris 2020

Follow this and additional works at: https://ir.lib.uwo.ca/etd

Part of the Investigative Techniques Commons

\section{Recommended Citation}

Harris, Aaron, "Ganglioside Detection from Formalin Fixed Human Brain Tissue Utilizing MALDI Imaging Mass Spectrometry" (2020). Electronic Thesis and Dissertation Repository. 6898.

https://ir.lib.uwo.ca/etd/6898

This Dissertation/Thesis is brought to you for free and open access by Scholarship@Western. It has been accepted for inclusion in Electronic Thesis and Dissertation Repository by an authorized administrator of Scholarship@Western. For more information, please contact wlswadmin@uwo.ca. 


\begin{abstract}
Matrix assisted laser desorption ionization (MALDI) imaging mass spectrometry (IMS) is largely performed on fresh frozen tissue whereas clinical tissue samples stored long term are fixed in formalin, and the fixation process is thought to cause signal suppression for lipid molecules. Studies have shown that fresh frozen brain tissue sections washed with ammonium formate (AF) prior to matrix application in the MALDI-IMS procedure display an increase in signal intensity and sensitivity for lipid molecules while maintaining molecular spatial distribution throughout the tissue. Work in this thesis compares MALDI data of ganglioside molecules from fresh frozen and post-fixed rat brain samples, and post-fixed human brain samples washed with AF. Results demonstrate that MALDI-IMS spectra for gangliosides are significantly enhanced in fresh frozen rat brain, formalin-fixed rat brain and formalin fixed human brain samples washed with AF. This method will allow for the analysis of gangliosides from formalin-fixed clinical samples, which can open additional avenues for neurodegenerative disease research.
\end{abstract}

Keywords: MALDI, Mass Spectrometry, IMS, Signal Enhancement, Gangliosides, GM1, Ammonium Formate, Matrix Assisted Laser Desorption Ionization Imaging Mass Spectrometry 


\section{Summary for Lay Audience}

Matrix assisted laser desorption ionization (MALDI) imaging mass spectrometry (IMS) is used to analyze molecules directly on tissue samples providing information about molecules present in the samples and where they are located. Tissue samples are often stored frozen or in a chemical solution called formalin, currently frozen tissue is largely used for MALDI as the chemical storage is thought to interfere with some types of molecules within tissue samples, such as lipid molecules. Some studies have demonstrated that molecules in frozen tissue can be better detected if the tissue is washed with ammonium formate (AF) before MALDI is performed, this method not only improves detection but also retains the location of molecules within the samples. This work aims to see if gangliosides, a lipid found in the brain, in human tissue stored in formalin can be analysed in MALDI imaging by comparing results from frozen and formalin rat brains and human brain samples washed with AF. Results show that MALDI data for gangliosides was improved in all types of tissue tested through the use of an AF wash. Images generated from MALDI were shown with molecule location retained after tissue washing. These results show that this method will allow for gangliosides to be analysed in samples stored in formalin in a clinical setting which can offer new research opportunities with neurodegenerative diseases. 


\section{Statement of Co-Authorship}

The following people and institutions contributed to the publication of work undertaken as part of this thesis:

Candidate - Aaron Harris, Department of Chemistry, University of Western Ontario Author 1 - Austyn Rosenburg, Vulnerable Brain Laboratory, Department of Anatomy and Cell Biology, University of Western Ontario

Author 2 - Rahul Mor, Vulnerable Brain Laboratory, Department of Anatomy and Cell Biology, University of Western Ontario

Author 3 - Ken Yeung, University of Western Ontario, Department of Chmistry/Department of Biochemistry, University of Western Ontario

Author 4 - Shawn Whitehead, Vulnerable Brain Laboratory, Department of Anatomy and Cell Biology, University of Western Ontario

Paper 1: Signal Enhancement of Gangliosides in MALDI Imaging Mass Spectrometry Analysis of Formalin Fixed Human Brain Tissue

Currently under review at the Journal of the American Society for Mass Spectrometry

Author Contributions:

Conceived and designed experiment: Candidate, Author 2, Author 4

Performed Experiments: Candidate, Author 2

Analyzed data: Candidate

Contributed biological tissue: Author 1

Wrote Manuscript: Candidate 


\section{Acknowledgements}

I'd like to thank my supervisors, Dr. Shawn Whitehead and Dr. Ken Yeung for their continued guidance and expertise as well as being a huge support during my time working in their labs. I have gained a lot of knowledge in the field of chemistry and I have learned a lot of transferable skills that will contribute to my future successes, thank you.

I'd like to thank all the members of the Whitehead and Yeung labs past and present for their guidance and memorable friendship and continuous encouragement. Special thanks to Sarah Caughlin for always helping me with many crucial aspects of the experiment as I was learning what research entailed as well as Kristina Jurcic for her teachings and expertise of MALDI-IMS instruments. I truly could not have done it without either of you, so thank you.

To my supervisory committee members Dr. Joseph Gilroy, Dr. Patrick O’Donoghue, and Dr. Martin Stillman. Thank you for your advice and expert guidance. I'd also like to extend my thanks to the staff and students of the Chemistry department.

I'd also like to thank family who always believed in me and were a constant support throughout my graduate studies. 


\section{Table of Contents}

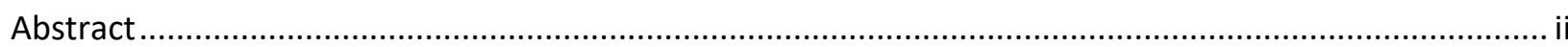

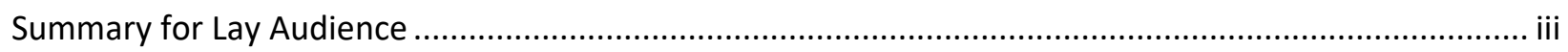

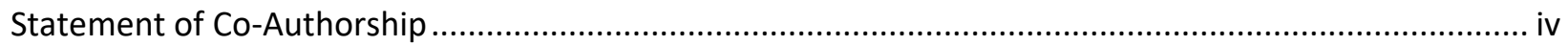

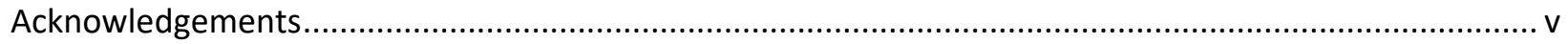

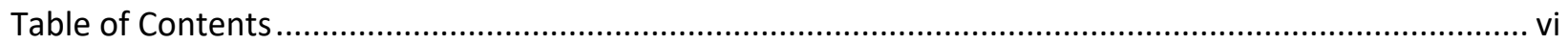

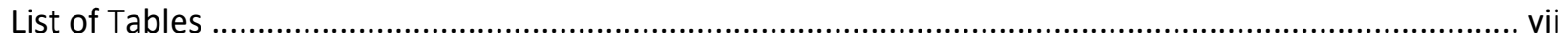

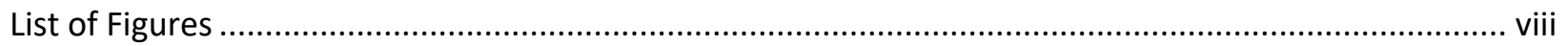

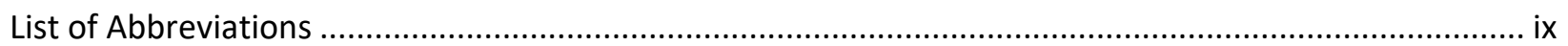

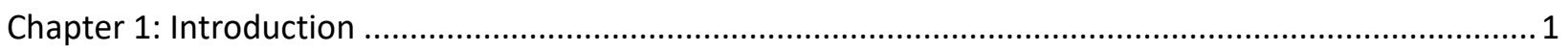

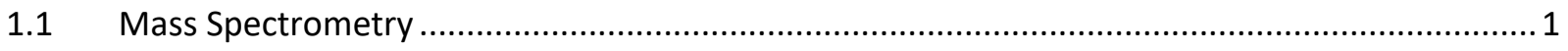

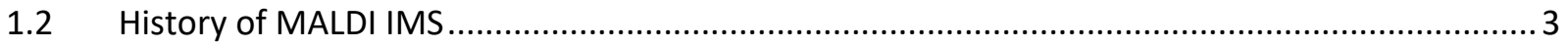

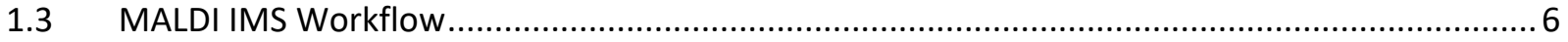

1.4 Tissue Storage: Fresh Frozen vs. Formalin Fixed ................................................................. 10

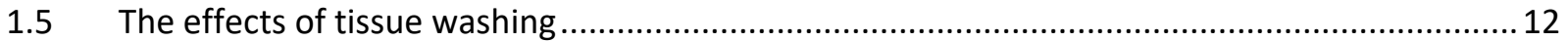

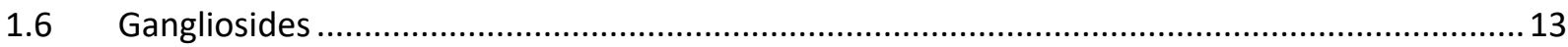

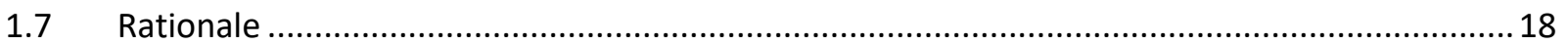

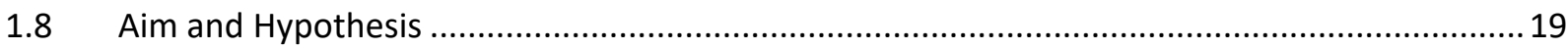

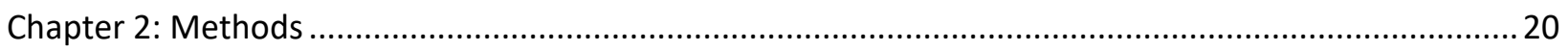

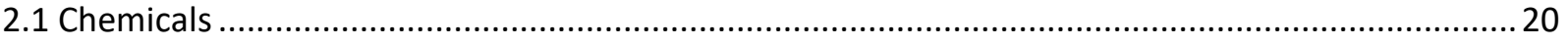

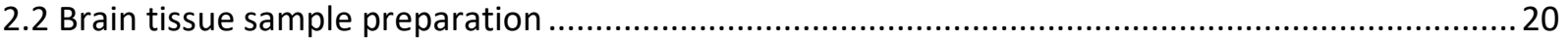

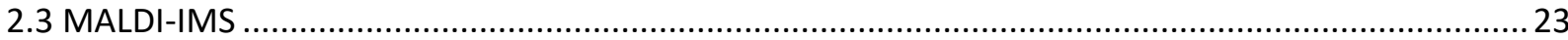

2.4 Processing of Molecular Image Data and Data Analysis ........................................................... 23

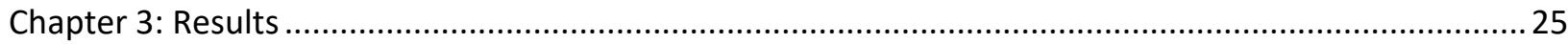

3.1 Enhanced GM1 detection following AF wash in fresh frozen rat brain .........................................25

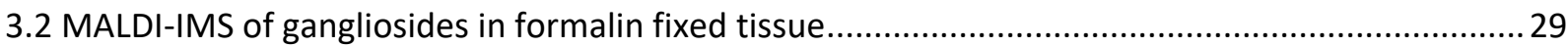

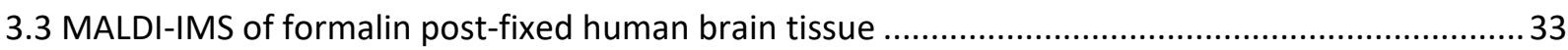

3.4 Comparison of Fresh Frozen and Formalin Fixed MALDI-IMS ….................................................. 39

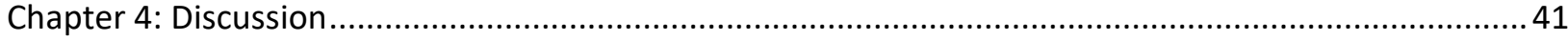

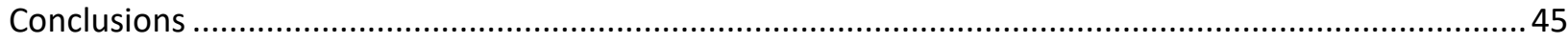

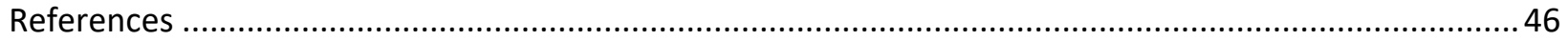

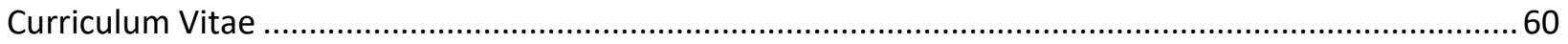




\section{List of Tables}

Table 1. The effect of AF wash on the MALDI-IMS signals of gangliosides in fresh frozen rat brain tissue

Table 2. The effect of AF wash on the MALDI-IMS signals of gangliosides in formalin postfixed rat brain tissue

Table 3. The effect of AF wash on the MALDI-IMS signals of gangliosides in formalin fixed human brain tissue

Table 4. Side by side comparison of degree of signal enhancement from all types of tissue tested 


\section{List of Figures}

Figure 1. An outline of the MALDI workflow

Figure 2. Ganglioside structure

Figure 3. Ganglioside biosynthetic and degradation pathways

Figure 4. Location of rat brain tissue sections used in experiments

Figure 5. The effect of AF wash on the MALDI-IMS signals of gangliosides in fresh frozen rat brain tissue

Figure 6. The effect of AF wash on the MALDI-IMS signals of gangliosides in formalin postfixed rat brain tissue

Figure 7. The effect of AF wash on the MALDI-IMS signals of gangliosides in formalin postfixed human brain tissue

Figure 8. On-tissue negative mode MS/MS identification of the major ganglioside species 


\section{List of Abbreviations}

MALDI

IMS

AF

MS

$\mathbf{m} / \mathbf{z}$

MS/MS

ESI

TOF

ITO

SIMS

DESI

OCT

DHB

SA

DAN

MRI

FFPE
Matrix Assisted Laser Desorption Ionization

Imaging Mass Spectrometry

Ammonium Formate

Mass Spectrometry

mass to charge ratio

Tandem Mass Spectrometry

Electrospray Ionization

Time of Flight

Indium Tin Oxide

Secondary Ion Mass Spectrometry

Desorption Electrospray Ionization

Optimal Cutting temperature

2,5-dihydroxybenzoic acid

Sinapinic Acid

1,5-Diaminonaphthalene

Magnetic Resonance Imaging

Formalin Fixed Paraffin Embedded 


\section{Chapter 1: Introduction}

\subsection{Mass Spectrometry}

Mass spectrometry (MS) is a versatile analytical technique that separates ions based on their mass to charge ratio (m/z). MS is able to analyze samples as solids, liquids and gases by converting sample molecules to ions from both simple and complex mixtures. It can be used to determine the masses and chemical identity or structure of analyte molecules and chemical compounds. Samples are generally broken apart or fragmented into ions, but can be ionized with minimal fragmentation, and separated by $\mathrm{m} / \mathrm{z}$ ratio which can be determined by subjecting them to a magnetic field. Results of MS are presented as a plot of sample intensity as a function of $\mathrm{m} / \mathrm{z}$, called a mass spectrum. A mass spectrometer consists of three main components; an ion source, which converts analyte molecules into ions, a mass analyzer that separates ions based on the masses and a detector, which measures the abundance of ions at each $\mathrm{m} / \mathrm{z}(1)$.

Several ionization techniques exist for various samples types and desired outcomes. These techniques can be divided into two broad categories, 'hard' ionization techniques wherein large amounts of residual energy are transferred to analyte molecules causing a high degree of fragmentation and 'soft' ionization techniques where a small amount of residual energy is transferred resulting in little to no fragmentation of analyte molecules. Hard ionization is useful for the detailed mass spectrum that a greater degree of fragmentation provides. When analyzed these mass spectra give important structural and characteristic information about molecules and compounds present in analyte samples. The most common example of a hard ionization technique is electron ionization, also known as Electron Impact Ionization, which involves the interaction of energetic electrons with analyte molecules to cause ionization $(1,2)$. Soft ionization is useful for 
analytes containing a larger number of different molecules. Since there is little fragmentation, each molecule will appear in the mass spectrum at respective $\mathrm{m} / \mathrm{z}$ ratios giving information on relative abundance of compounds present in a sample. It is possible to obtain further structural information for specific molecules by selecting them after they have passed through the mass analyzer, fragmenting the selected molecule(s) and accelerating the fragments through a second mass analyzer resulting in a mass spectrum that can be analyzed to determine structural characteristics of the molecule, this is known as tandem mass spectrometry (MS/MS). Common examples of soft ionization techniques include Electrospray Ionization (ESI) which involves using an aerosol created by applying a high voltage to a liquid (1,3) and Matrix Assisted Laser Desorption Ionization (MALDI) which will be explained in detail in the next section. Once ionized, molecules are transported to the mass analyzer via magnetic or electric fields.

Mass analyzers act to separate ions based on $\mathrm{m} / \mathrm{z}$ ratio have several important characteristics including mass accuracy, how close the detected $\mathrm{m} / \mathrm{z}$ is to the actual $\mathrm{m} / \mathrm{z}$ of the analyte molecule, mass resolving power, the ability to distinguish between two peaks in a mass spectrum that are close in mass, and mass range, the range of masses a given analyzer is able to analyze. Typical mass analyzers include quadrupole mass analyzers that use oscillating electric fields to selectively stabilize and destabilize ions passing through 4 parallel rods generating a radio frequency quadrupole field allowing only selected ions to pass through at a given time (4) and time-of-flight (TOF) mass analyzers that accelerate ions through a constant potential separating molecules based on the time it takes for each to reach the detector (5). Ion traps are also used as mass analyzers such as the quadrupole ion trap which operates on the same principles as quadrupole mass analyzers but ions are trapped and selectively ejected and orbitraps that electrostatically trap ions in orbit around a central electrode causing oscillation and generating images whose frequencies 
can determine $\mathrm{m} / \mathrm{z}(6)$. The detector then records the charge or current of the separated ions measured as they contact or pass by a surface.

\subsection{History of MALDI IMS}

MALDI Imaging Mass Spectrometry (IMS) is at the forefront of molecular imaging approaches for the spatial visualization of molecules in biological samples and is used to detect and localize proteins $(7,8)$, peptides (9), lipids (10) and metabolites (11). MALDI is a MS ionization technique that utilizes an energy absorbing matrix, which is then ablated with a laser to create ions from a wide range of molecules. This method can be used to analyze molecules in a mixture with the matrix, as well as analyzing molecules directly from sectioned tissue samples mounted onto semi conductive indium tin oxide (ITO) slides. MALDI has been used to analyze many different types of biomolecules, such as proteins, peptides and lipids, as well as large organic molecules that tend to fragment during the ionization process.

The term MALDI was first coined by Franz Hillenkamp and Michael Karas in 1985. They discovered that alanine, an amino acid, was ionized more effectively when it was mixed with another amino acid, tryptophan. In this instance the tryptophan was acting as a 'matrix', absorbing the energy of the laser and assisting with the ionization of alanine. In 1987, Koichi Tanaka and his colleagues used a method they termed 'ultra fine metal plus liquid matrix method' to ionize and detect biomolecules exceeding 30,000 Daltons in size. This method utilized a matrix consisting of $30 \mathrm{~nm}$ cobalt particles in glycerol with a $337 \mathrm{~nm}$ nitrogen laser as the ionization source and is considered a breakthrough point for large molecule imaging in MALDI. Tanaka was later awarded one quarter of the Nobel Prize for Chemistry in 2002 for demonstrating that, with proper combination of laser intensity and matrix composition, large molecules such as proteins can be ionized (12). Soon after, Karas and Hillenkamp were able to ionize proteins exceeding 65 
$\mathrm{kD}$ in size utilizing a $266 \mathrm{~nm}$ laser and a nicotinic acid matrix (13). In the 1990s, relatively inexpensive $337 \mathrm{~nm}$ nitrogen lasers became available bringing with it the introduction of commercial MALDI instruments giving an increasing number of researchers access to MALDI instruments (14).

MALDI is one of several MS ionization techniques that are capable of analyzing molecules directly from intact tissue sections and is capable of generating images containing MS data, hence the term IMS $(15,16)$. IMS is a technique that acquires region specific molecular data from intact biological tissue samples (17-21). Mass spectrometers provide a unique form of imaging utilizing high sensitivity and molecular specificity to generate images that visually represent the molecular biology of the specimen being analyzed. Important in IMS, is the preservation of spatial integrity of the sample being analyzed, requiring data acquisition and sample preparation protocols to differ from other mass spectrometric techniques, such as secondary ion mass spectrometry (SIMS) (22) and Desorption Electrospray Ionization (DESI) (23).

The general process of the MALDI IMS protocol requires the tissue sample to first be sectioned and mounted on a conductive slide. The matrix is then applied to the tissue section which extracts analytes and aids in the desorption/ionization of analyte molecules during laser ablation. Direct analysis of the sample is then performed by laser ablation in a raster or grid pattern, resulting in the generation of a mass spectrum for each point the laser ablated. With the cumulative data obtained from laser ablation, an image is formed where each pixel contains MS data and is visualized as an intensity map that can be adjusted to focus on different molecules within the mass range scanned. The distance between each point of laser ablation determines the spatial resolution of the image obtained. In other words, the closer together each point of ablation is, the smaller the pixel size within the generated image and the higher the spatial resolution. MALDI data is 
generally acquired in the range of 50 and $200 \mu \mathrm{m}$ but some instruments are capable of imaging with a resolution less than $1 \mu \mathrm{m}(24)$.

MALDI has various advantages that make it ideal for the imaging of biological samples. As previously mentioned, MALDI is a 'soft ionization' technique allowing for analysis of molecules in a wide range of sizes from hundreds of daltons to $100 \mathrm{kDa}$ and the spectra generated through MALDI are often composed of singly charged ions allowing for easier analysis of larger molecules such as proteins (25). MALDI is also capable of focusing on very specific regions of tissue samples due to the use of a laser as the ionization source, which can be directed to histologically unique regions instead of imaging an entire tissue section.

There are two common methods of obtaining region specific information from tissue samples in MALDI. The first, used in the work depicted in this thesis, is to image the entire section of tissue and obtain intensity maps of the molecules of interest, which can be represented in a false color display. Matrix is applied uniformly over the tissue section and a complete data set of many hundreds or thousands of $\mathrm{m} / \mathrm{z}$ values is obtained in data acquisition. The second method is to obtain data from small selected areas of a tissue sample with region selection directed often through microscopy or other imaging techniques, termed histology directed molecular imaging (26). This technique requires that matrix only be applied to selected areas, thus requiring less mass spectra to be obtained, reducing file size and acquisition time by not imaging entire sections and selected areas can be visualized by superimposing the MALDI image with another image obtained from the technique used to initially select the region. Both approaches are utilized based on the desired outcomes of the experiment performed. For example, whole section imaging is used to assess the distribution of molecules within the tissue and the histology directed method can be used to assess selected regions with specific cell types or morphological differences, often assisted 
by a pathologist or biologist. The histology directed approach has been applied to both fresh frozen and formalin fixed tissue samples (26-35), however imaging of entire sections has yet to be explored in formalin fixed tissue to our knowledge. Both methods of tissue preservation each have their respective strengths and weaknesses which will be explored in a later section.

\subsection{MALDI IMS Workflow}

Sample preparation, including tissue storage, sectioning, matrix selection, and method of matrix deposition all play a critical role in determining the quality of MALDI IMS data (34). The first step in preparation of stored tissue samples for MALDI analysis is the sectioning of tissue. Although a straightforward process, utilizing a cryomicrotome to obtain thin sections desired for MALDI analysis, there are special considerations that must be taken for MALDI samples. Often tissue is stored in embedding media such as optimal cutting temperature (OCT) compound, a polymer that aids in positioning samples for sectioning and is useful for histological sectioning. This polymer causes ion suppression, impacting the number of ions detected in MALDI analysis $(37,38)$. To overcome this issue, our lab freezes specimens directly to the cryotome chuck using water. Ionization efficiency, referring to the number of generated ions per molecules consumed, is dependent on the thickness of sections analyzed (39). It is recommended to use thinner tissue sections $(2-5 \mu \mathrm{m})$ for molecules of higher molecular weight, such as proteins and thicker sections $(5-20 \mu \mathrm{m})$ for lower molecular weight analytes $(40)$.

Tissue sections can then be thaw mounted to a solid surface by inverting a warm slide overtop of the tissue section, allowing the section to adhere to the surface or place sections on a slide of equal temperature to the section and warming from the underside to mount the section. Slides are often conductive to support application of the potential required to accelerate ions in the mass spectrometer source. For these purposes, ITO slides are often used as it provides the electrical 
conductance preferred and allows for subsequent microscopic analysis or staining of tissue sections if desired. Tissue staining is often performed on serial sections and identifying tissue landmarks to locate regions of interest within MALDI samples (22) but some stains can be performed on sections prior to MALDI analysis and have been shown to be compatible with MALDI (41).

The next step in MALDI preparation is the application of the matrix which absorbs energy from the laser and transfers it to the analytes in the gas phase creating a plume and promoting ionization $(42,43)$. Matrix molecules ionize analytes molecules through proton transfer, often forming singly protonated $[\mathrm{M}+\mathrm{H}]^{+}$ions or multiply protonated $[\mathrm{M}+\mathrm{nH}]^{\mathrm{n}+}$ ions, and singly deprotonated $[\mathrm{M}-\mathrm{H}]^{-}$ions. Different matrices have been developed for various analyte classes such as 2,5-dihydroxybenzoic acid $\left(\mathrm{DHB}, \mathrm{C}_{7} \mathrm{H}_{6} \mathrm{O}_{4}\right)$ for imaging peptides, proteins, lipids and drugs $(37,44,45), 3,5$-dimethoxy-4-hydroxycinnamic acid for proteins (SA, or sinapinic acid, $\left.\mathrm{C}_{11} \mathrm{H}_{12} \mathrm{O}_{5}\right)$ $(37,45,46)$ and 1,5-diaminonaphthalene (DAN, $\left.\mathrm{C}_{10} \mathrm{H}_{10} \mathrm{~N}_{2}\right)$ for lipids $(47,48)$.

Various methods have been developed for the application of matrix in liquid form, whereby a powdered matrix is dissolved in a solvent, or solid form to tissue sections. In liquid form, matrix is applied via as aerosol spray that can be done manually $(37,49)$, relying on the abilities of the analyst, or more reliably through an automated sprayer where the matrix is applied in a repeatable and programmable way $(50,51)$. Liquid application of matrix, while most common, presents an increased likelihood of large crystals forming on the surface of the sample as well as an increased risk of molecular delocalization (52), both of which can reduce detection and imaging quality in MALDI analysis. Alternatively, sublimation is a dry approach to matrix application used to make uniform coatings of matrix without the limitations present in liquid approaches. The matrix is heated under vacuum in a sublimation chamber while the slide is inverted and affixed to a cool 
surface. The matrix sublimes and condenses on the cold surface of the sample, the amount sublimated is controlled by the temperature the matrix is heated to and time in which the heat is applied (53). Sublimation also acts to remove non-volatile impurities during the sublimation and sample coating process (53). After matrix application the samples are ready for MALDI analysis (Figure 1). 


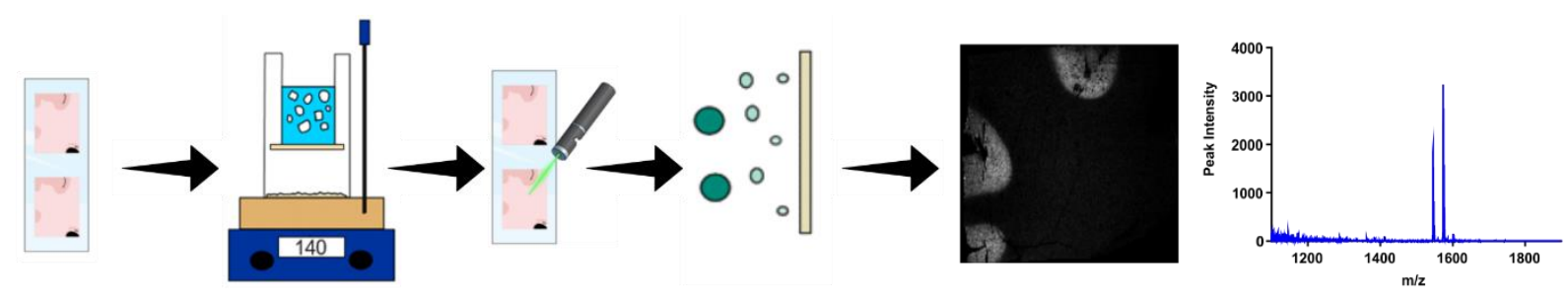

Tissue Sections Matrix Application Laser TOF Ion Thaw Mounted via Sublimation Ablation Detection

Image and Data Accquisition

Figure 1. An outline of the MALDI workflow. The steps in a typical MALDI workflow consist of tissue sectioning and mounting on a conductive slide followed by matrix application. The samples are then placed in the MALDI instrument for analysis where laser ablation occurs causing molecules to be ionized in a plume of matrix and analyte molecules. An image is generated which can then be analyzed to obtain mass spectrometric data and molecular information. 


\subsection{Tissue Storage: Fresh Frozen vs. Formalin Fixed}

A critical step in the MALDI workflow is that of sample preparation when it comes to optimizing sensitivity and spatial resolution for the desired analytes and the type of tissue being tested. Thus, preservation of sample tissue is an important factor as failure to preserve tissue in a timely manner may result in morphological changes and degradation of analytes within the tissue (54-57). Minimizing time between tissue harvest and preservation limits the exposure of tissue samples to potential degradation. The main technique used to preserve samples intended for MALDI analysis is snap freezing where the tissue sample is exposed to a cryogen such as liquid nitrogen or dry ice. Tissue, when first harvested is prone to deformation and care must be taken when preserving samples, a useful technique is to place tissue samples on aluminum foil and float it on liquid nitrogen and allowing the sample to freeze before fully wrapping the tissue in foil and immersing in the cryogen (24). This technique allows for slower freezing of samples compared to direct immersion and is useful for more delicate tissue that tends to fracture upon freezing, such as brain tissue. Whole tissue samples can be stored at $-80^{\circ} \mathrm{C}$ without any detrimental effects on MALDI data for at least a year $(37,58)$ though tissue types can vary widely, and prolonged storage can have differing effects.

Long-term tissue storage however, involves fixing tissue samples in formaldehyde, paraformaldehyde or formalin fixatives; which are effective methods of preserving tissue specimens for future investigation (59). Moreover, immersion in fixative solutions is routinely performed on clinical samples, such as human brain tissue, for neuropathological analysis and offers an alternative method of tissue storage allowing samples to be preserved at room temperature for an extended period of time. Through the cross-linking of proteins, fixatives act to disable intrinsic biomolecules and due to the toxicity of the fixative prevents extrinsic damage 
from microorganisms. Cross-linking also helps to preserve the morphology of tissue samples by increasing the rigidity. Even more so, clinical human brain samples are often sectioned in thicker blocks and then fixed in formalin, known as post-fixation, which can then be used in various ways, two of which being magnetic resonance imaging (MRI) and histological purposes. Formalin fixed tissue samples can then remain stored in formalin for many years, to be kept at cool temperatures or can be dehydrated and embedded in paraffin, known as formalin fixed paraffin embedded (FFPE), for easier sectioning of small samples while allowing the tissue to remain stable for many years at room temperature. FFPE samples can be de-paraffinized for analysis through solvent washes in xylene and alcohols (60). Formalin fixation inhibits the analysis of tissue samples through MALDI as fixation often alters the cells within tissue, especially proteins due to protein cross-linking in the fixation process (61). Formalin fixation also poses a problem for lipid imaging using MALDI-IMS since it has previously been thought that lipids are largely washed away during the fixation process (62). However, recent studies have shown that lipid ionization from fixed tissue samples is possible $(63,64)$.

Clinically, MALDI-IMS of fixed tissue has been used previously to profile lipids and proteins in suspected cancerous tissue $(65,66)$ and has also been previously used to profile lipid changes in the brains of alcoholics (67). High resolution imaging of formalin fixed tissue has been obtained in various clinical studies involving the mapping of cysteine rich proteins in skin (68) and mapping of extracellular proteins in human liver tissue (69). MALDI MS imaging of formalin fixed brain tissue has only been performed in various preclinical studies including imaging of mouse and rat brain sections to optimize the fixation procedure for MALDI analysis $(63,70)$ and has yet to be performed on formalin fixed clinical brain samples. Thus far MALDI MS imaging of lipids in the human brain has been performed solely in fresh frozen samples for studies such as examining grey 
and white matter phospholipid distributions $(71,72)$ as well as lipid mapping in the visual cortex (73) and optic nerve (74). To our knowledge high resolution imaging of certain lipid types in fixed human brain tissue has yet to be explored.

1.5 The effects of tissue washing

Biological samples can contain many types of molecules in varying concentrations across tissue types and some of the most abundant species present within tissue samples can inhibit detection of lesser species making them more difficult to analyze. For example, proteins and peptides can be made more difficult to analyze in the presence of salts and lipids $(75,76)$. Problems that may be encountered due to the presence of other molecular species, such as poor crystallization, ion suppression and adduct formation can be overcome by washing the tissue samples prior to the application of matrix in the MALDI procedure.

Washing protocols need to be optimized for the analyte of interest so as to remove the unwanted molecules while retaining the spatial distribution of analyte molecules within the tissue and sensitivity of the instrument for the molecule of interest. Most commonly used is a series of ethanol washes for enhancing the sensitivity of proteins in MALDI analysis $(37,41,77,78,79)$, though other washes such as chloroform or xylene have been used to remove lipids from tissue samples and improve protein detection (58). Although many washes are known to delipidate tissue samples, there are some washes that have been shown to enhance lipid signal detection in MALDI IMS (80-82). Specifically, an ammonium formate (AF) wash has been shown to effectively increase lipid signal to noise detected, allowing for better detection of lipids in fresh frozen rodent brain tissue $(80,83)$. The wash is thought to accomplish this either by the formation of adducts or the removal of salt constituents from the tissue while still retaining the ability to ionize 
biomolecules and maintaining the spatial distribution of the molecules of interest. Currently, this method of lipid enhancement has not been explored for formalin fixed tissue in MALDI imaging.

\subsection{Gangliosides}

With many clinical samples stored in formalin, the ability to analyze lipids in MALDI IMS could hold potential for improving neurodegenerative disease research as lipids are essential molecules in the human body and are associated with many biological functions. Gangliosides, for example, are the most prominent lipid type within the brain accounting for $1 \%$ of lipid mass $(84,85,86)$. Gangliosides are glycosphingolipids that consist of a ceramide base, which can vary in sphingosine chain length, attached to oligosaccharide chains that can be mono- to poly-sialylated (Figure 2). These molecules are critical components of both neuronal and glial lipid membranes within the brain and are important for many neuronal functions including cell adhesion, differentiation and migration, as well as synaptic transmission and myelin genesis and stability (87-91). 

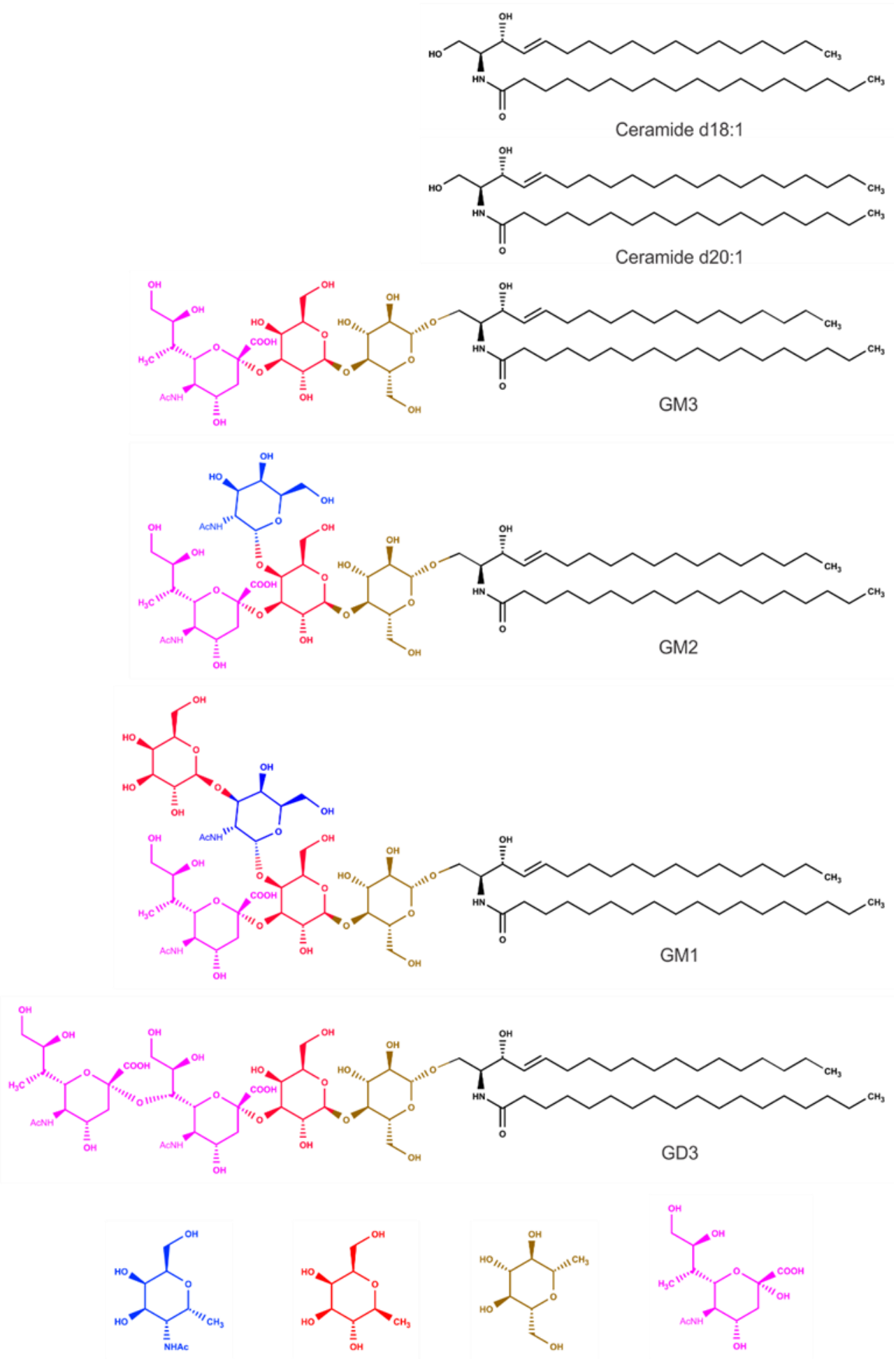

Galactose

Galactosamine

Glucose

Sialic Acid 
Figure 2. Ganglioside structure. Gangliosides contain a hydrophobic ceramide moiety that consists of a long-chain amino alcohol, sphingosine, which is acylated with a fatty acid on the amino group. The polar head is an oligosaccharide that contains a sialic acid.

An understanding of lipid distribution throughout the brain is critical, not only due to their many essential functions, but also because varied levels of these molecules have been associated with neurodegenerative diseases. For example, reduced levels of GM1, a key brain ganglioside, has been linked to Huntington's Disease, Parkinson's Disease and Alzheimer's disease $(88,92,93)$; and is currently being investigated for its therapeutic potential $(94,95,96)$. On the other hand, simpler ganglioside species such as GM2 and GM3 have been linked to brain injury (Figure 3). Preclinical studies have demonstrated that ganglioside composition changes during aging such that complex gangliosides GM1 and GD1a are decreased while simple gangliosides such as GM2 and GM3 are increased (87). Additional work in the aging rat has shown that the sphingosine base length of gangliosides shifts from 18 carbons in length to 20 carbons in length during normal aging (10). Although preclinical models are valuable to better understand the role of lipids like gangliosides in brain aging and disease, detection of compositional changes of gangliosides within human brain tissue is essential for further understanding of brain function. 


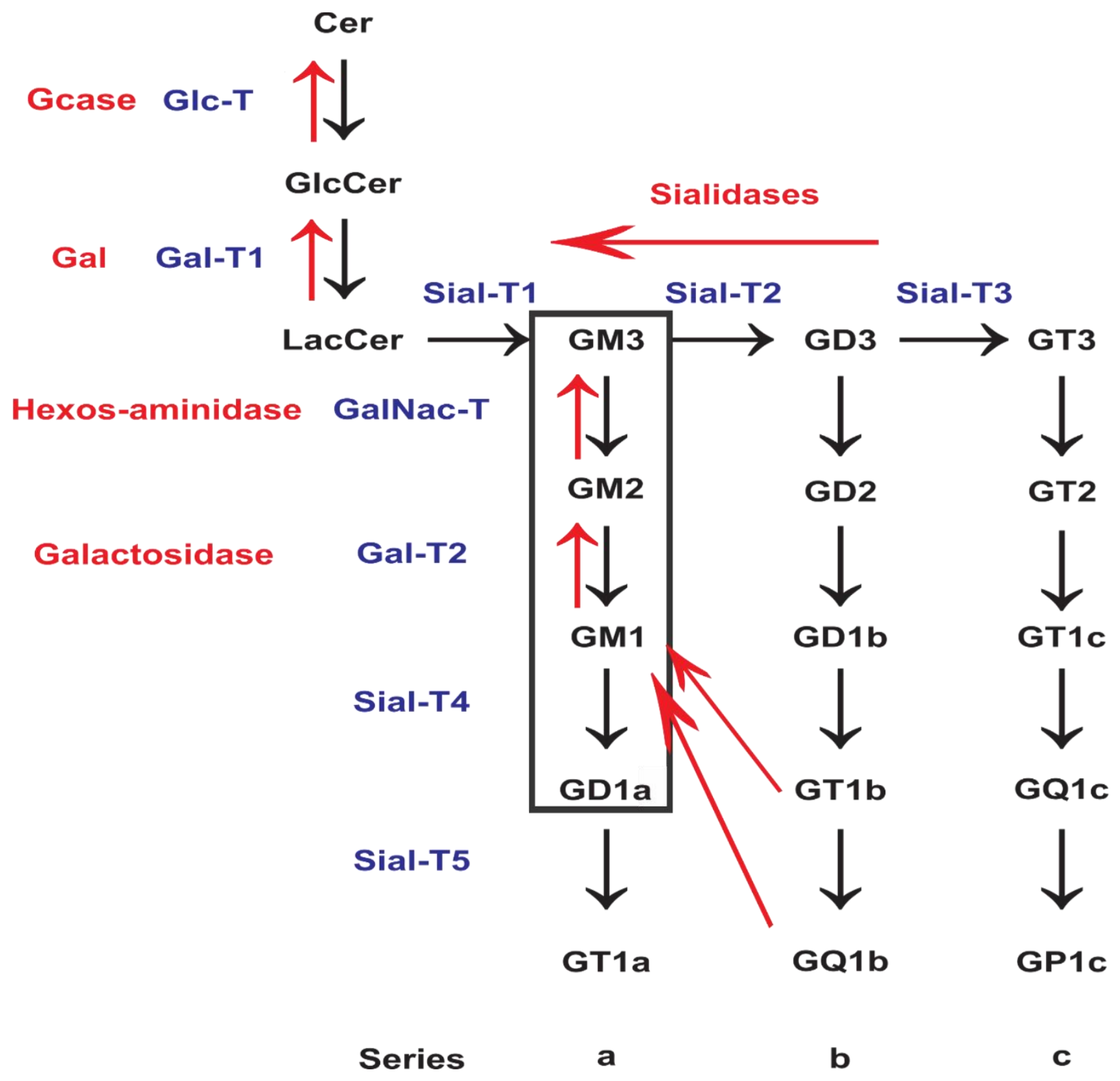

Figure 3. Ganglioside biosynthetic and degradation pathways. Gangliosides are synthesized and degraded in a stepwise manner. Synthesis, outlined by the black arrows, starts with the lipid precursor ceramide which is generated in the endoplasmic reticulum, and their synthesis is continued in the golgi complex via glycosyltransferases and sialyltransferases, adding sugar and sialic acid residues respectively. Ganglioside degradation, indicated by red arrows, takes place in the acidic compartments endosome and the lysosome, it is catalyzedcatalyzed by the glycosidases 
and the sialidases that sequentially split off the carbohydrate and sialic acid residues $(97,98)$. The black outline indicates the most common ganglioside species found within the brain. GalNAc-T: Nacetylgalactosaminyltransferase or GM2/ GD2/ GT2 synthase, GalT-1: galactosyltranferase I, GalT-2: galactosyltranferase II or GM1 synthase, Glc-T: glucosyltransferase, Sial-T1: sialyltransferase I or GM3 synthase, Sial-T2: sialyltransferase II or GD3 synthase, Sial-T3: sialyltransferase III or GT3 synthase, Sial-T4: sialyltransferase IV or GD1a synthase, Sial-T5: sialyltransferase V or GT1a synthase, Gal: galactosidase, GCase: glucocerebrosidase. 


\subsection{Rationale}

MALDI IMS is a powerful technique able to obtain spatial information of molecules within biological samples directly from intact tissue sections. The capabilities of MALDI IMS are limited by the types of tissue samples currently able to be analyzed, such as formalin fixed tissue samples, which are believed to have lipid signal suppression due to the fixation process. Therefore, a method of signal enhancement that would allow formalin fixed tissue to be analyzed via MALDI IMS would open many avenues in clinical research as many clinical samples are fixed in formalin for long term storage.

Post-mortem tissue is crucial in disease research and the understanding how neurological diseases affect the brain. Studies have demonstrated that an aqueous wash of sectioned tissue, prior to matrix application, significantly enhances MALDI IMS signal. In particular, AF has been shown to be effective at enhancing lipid signal obtained from fresh frozen tissue sections, though it has not been thoroughly explored for formalin fixed tissue. Therefore, work in this thesis aims establish a method of MALDI analysis of gangliosides in formalin fixed tissue utilizing an AF wash. Work herein demonstrates that ganglioside imaging of formalin fixed tissue is possible while retaining the spatial information of gangliosides within tissue sections. This allows for visualization and quantification of ganglioside molecules within formalin fixed tissue samples that have been stored for extended periods of time, opening new avenues to further the understanding of how the diseased brain changes on a molecular level. 


\subsection{Aim and Hypothesis}

Aim: Investigate the viability of MALDI IMS in imaging gangliosides retained in formalin fixed tissue that has been stored for long periods of time utilizing an AF wash to enhance the signal from the tissue.

Hypothesis: Imaging of gangliosides from formalin fixed clinical tissue samples will be possible by improving ganglioside detection in negative ion mode MALDI IMS. 


\section{Chapter 2: Methods}

\subsection{Chemicals}

Ammonium Hydroxide, Formic Acid, and 1,5-Diaminonapthalene (DAN, Sigma-Aldrich, Oakville, ON, Canada). A buffer solution of Ammonium Formate was prepared from $0.05 \mathrm{M}$ solutions of ammonium hydroxide and formic acid in equal amounts to create a $0.05 \mathrm{M} \mathrm{AF}$ solution.

\subsection{Brain tissue sample preparation}

All animal protocols were approved by the Canadian Council on Animal Care and Western University Animal Care Committee (2016-027). Rat brains were isolated from 3-month old male Wistar rats. Rat brains were flash-frozen in dry ice immediately after dissection, sections of these brains were used as "fresh frozen tissues" $(n=5)$ and sections were immersed in formalin post sectioning to be used as "post-fixed tissues" $(n=5)$. Fresh frozen tissue was stored at $-80^{\circ} \mathrm{C}$ until use. Tissue blocks were obtained from the cerebral cortex of post-mortem human brains $(n=5)$ containing both grey and white matter with the help of a neuropathologist. Non-identified human pathological specimens from post-fixed brains were stored in $10 \%$ formalin for variable lengths of time (from 5 to 15 years). Human post-fixed brain tissue was maintained in formalin and stored at $-4^{\circ} \mathrm{C}$ until use.

Brain samples were sectioned using a cryostat (Thermo-Fisher Scientific CryoStar NX50, Toronto, Canada) at a thickness of $10 \mu \mathrm{m}$ and thaw mounted onto glass slides, $75 \mathrm{~mm}$ by $25 \mathrm{~mm}$, coated with electrically conductive Indium-Tin-Oxide (ITO) (Hudson Surface Technology Inc., Old Tappan, NY, USA). Rat brain sections to be post-fixed were subsequently immersed in $10 \%$ 
formalin for 15 minutes, then allowed to dry for 5 minutes open to the air and another 10 minutes in a desiccator under vacuum. Sections of rat brain were taken from the area depicted in Figure 4 and sections of human tissue were taken from the brain area depicted in Figure

$\mathrm{AF}$ solution was kept at a $\mathrm{pH}$ of 6.4 and a temperature of $4^{\circ} \mathrm{C}$, the $\mathrm{AF}$ wash was performed by submerging the desired tissue sections mounted on glass slides in the $0.05 \mathrm{M}$ AF solution for 30 seconds, the slides were then allowed to dry for 5 minutes open to the air and 10 minutes in a desiccator under vacuum as previously described (80). 


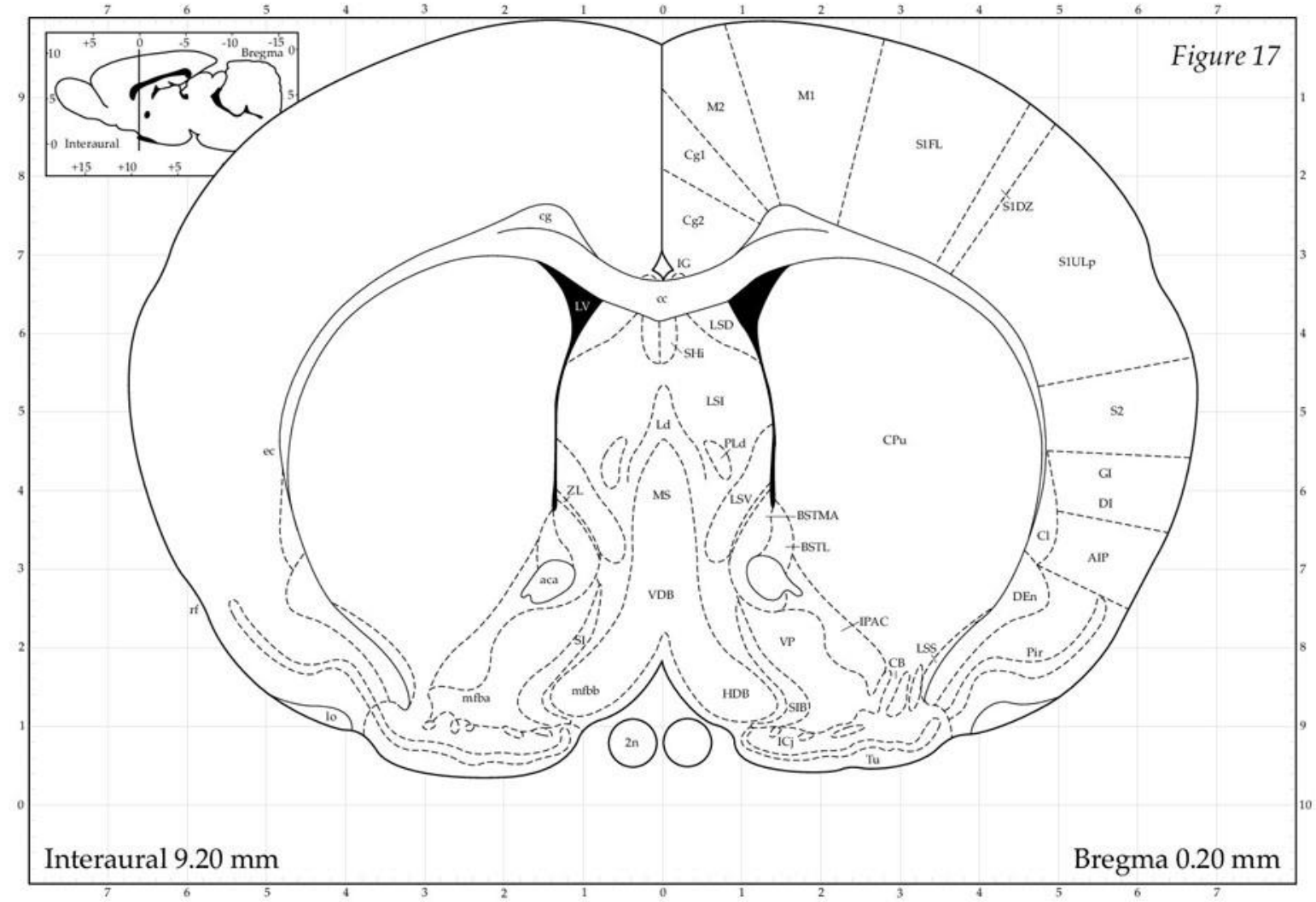

Figure 4. Location of rat brain tissue sections used in experiments. Rat brain atlas depicting brain region that fresh frozen and post fixed rat brain sections were obtained from (99). 


\subsection{MALDI-IMS}

Slides mounted with rat brain tissue sections were coated with a thin layer of 1,5Diaminonapthalene (DAN, Sigma-Aldrich, Oakville, ON, Canada) matrix via sublimation for 8 minutes at $140{ }^{\circ} \mathrm{C}$. The slides were incubated at $-20^{\circ} \mathrm{C}$ overnight prior to MALDI IMS. The assembly of the apparatus and sublimation of matrix was performed as previously described (48).

Mass Spectrometry data were obtained using a Sciex 5800 MALDI TOF/TOF MS instrument (Framingham, MA, USA). Data acquisition and data processing were respectively done using a TOF/TOF Series Explorer and Data Explorer software (Sciex). The instrument is equipped with a $349 \mathrm{~nm} \mathrm{Nd:YLF} \mathrm{OptiBeam} \mathrm{On-Axis} \mathrm{laser} \mathrm{and} \mathrm{set} \mathrm{to} \mathrm{a} \mathrm{laser} \mathrm{pulse} \mathrm{rate} \mathrm{of} 400 \mathrm{~Hz}$. Reflectron negative mode was used and was externally calibrated at $50 \mathrm{ppm}$ mass tolerance and internally at $10 \mathrm{ppm}$. Image acquisition was performed in reflectron negative ion mode, with an $80 \mu \mathrm{m}$ laser step distance. A mass spectrum with a 1000-2000 m/z range was acquired for each laser shot.

\subsection{Processing of Molecular Image Data and Data Analysis}

MS imaging data were visualized using TissueView software (Sciex). All images were optimized for visual expression, the color intensities do not show the same signal intensity across different images. Independent t-tests were performed on each pair of control and wash tissue to test for significant increase in signal intensity. Molecular identities were determined using LipidMAPS with further identification of ganglioside species through tandem mass spectrometry (MS/MS) (Figure 8).

MS data exported from TissueView was analyzed in Prism 7 software. Area under curve (AUC) analysis was generated for each peak of interest, obtaining an area ratio of individual peak area to area under the entire spectrum. Fold increase values for each peak were obtained by 
comparing washed AUC values/Control AUC values. Values shown in figures and tables are averaged from all trials of the respective tissue types, $n=5$ for each tissue type. 


\section{Chapter 3: Results}

3.1 Enhanced GM1 detection following AF wash in fresh frozen rat brain

To evaluate the effectiveness of the AF wash, MALDI-IMS was first performed on adjacent sections of fresh frozen coronal rat brain tissue sections to observe the difference in spatial distribution both d18:1 and d20:1 species of GM1 within the striatum (Figure 5A). The spatial distribution of d18:1 GM1 molecules in tissue was preserved following the AF wash while demonstrating an increase in signal intensity throughout the intensity map image. Similar effects were observed for the less abundant d20:1 species of GM1. The mass spectra of the striatum region (dotted circle in Figure 5A) obtained showed a significant increase in signal for the total spectrum of AF washed tissue (Figure 5B) as well as for the individual GM1 peaks (Figure 5B) while maintaining a similar signal to noise ratio as the unwashed tissue. To assess the effectiveness of the wash, the signals for $\mathrm{AF}$ washed and control unwashed tissues were quantified. A comparative analysis was then performed which showed an almost 3-fold increase (Figure 5D, $\mathrm{p}<0.05)$ in GM1 d20:1 signal as a result of washing with AF. Similar increases in ganglioside signal were observed in white matter specific regions, such as the corpus callosum (Red Dot in Figure 5A, Figure 5E-F), and grey matter specific regions, such as the cerebral cortex (Blue Dot in Figure 5A, Figure 5H-J). To further asses the AF wash, other ganglioside signals appearing in Figure 5B were quantified and are outlined in Table 1. 

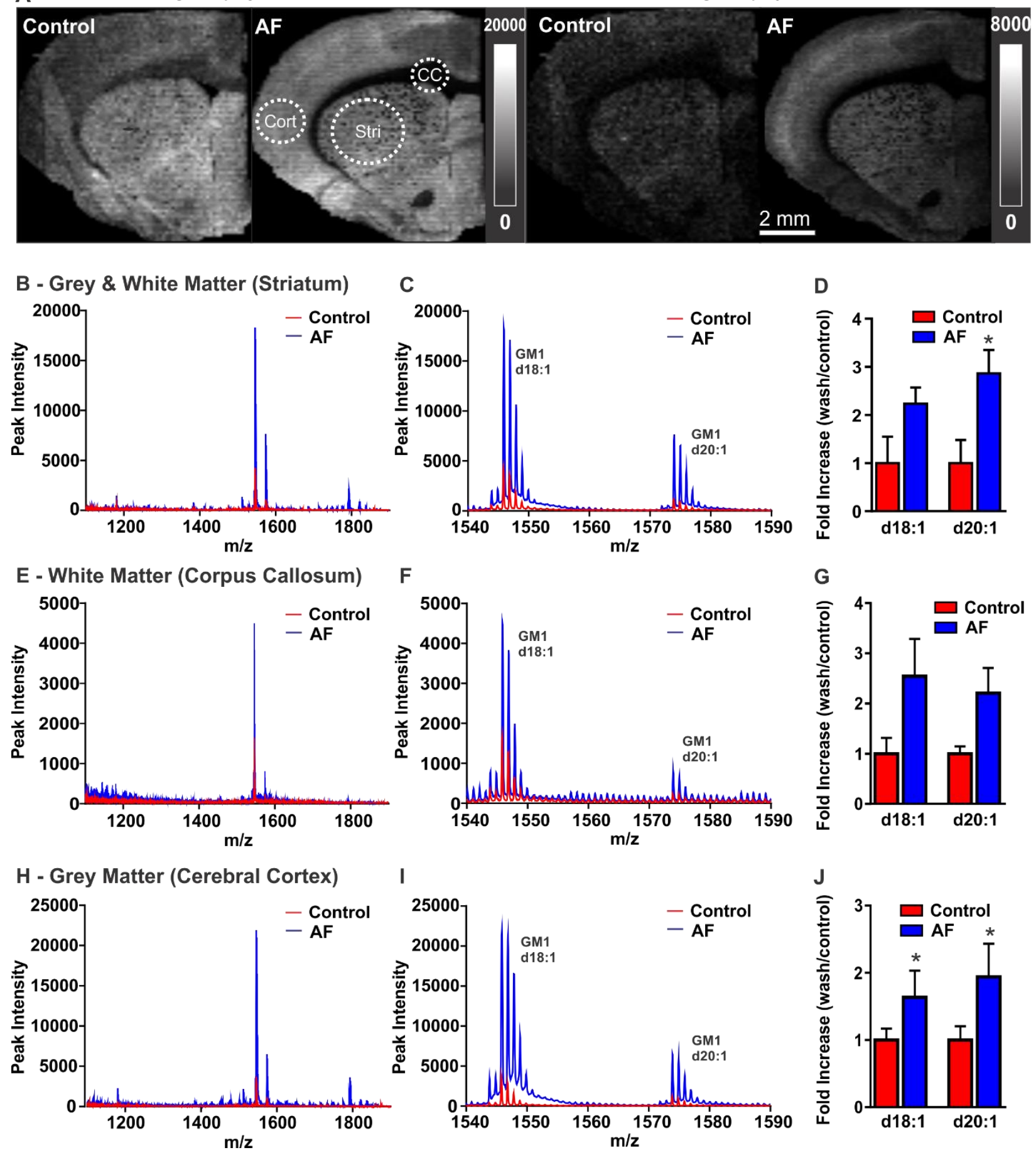

Figure 5. The effect of AF wash on the MALDI-IMS signals of gangliosides in fresh frozen rat brain tissue. A comparison of ganglioside GM1 detection in the white and grey matter areas of fresh frozen rat brain tissue from control and AF washed samples. Signal enhancement is 
observed from the mass spectra and degree of signal enhancement can be seen through a comparative area under curve analysis of GM1. (A) MALDI-IMS generated intensity maps of GM1 d18:1 and d20:1 from control and AF washed fresh frozen rat brain tissue. Striatum, corpus callosum and cortex regions of the brain labelled with a dotted white circle, a red dot and blue dot respectively. (B) Mass spectra of gangliosides and other lipids from the striatum (dotted circles in A). (C) Mass spectra of GM1 d18:1 and d20:1 from the striatum (D) Quantification of GM1 d18:1 and d20:1 species in the striatum. (E) Mass spectra of gangliosides and other lipids from the corpus callosum. (F) Mass spectra of GM1 d18:1 and d20:1 from the corpus callosum (G) Quantification of GM1 d18:1 and d20:1 species in the corpus callosum. (H) Mass spectra of gangliosides and other lipids from the cerebral cortex. (I) Mass spectra of GM1 d18:1 and d20:1 from the cerebral cortex. (J) Quantification of GM1 d18:1 and d20:1 species in the cerebral cortex. * indicates statistical significance, Student's t-test, $\mathrm{p}<0.05, \mathrm{n}=5$ for each experimental group. 


\begin{tabular}{|c|c|c|c|c|c|c|c|}
\hline \multirow{3}{*}{$\begin{array}{l}\text { Molecular } \\
\text { Identity }\end{array}$} & \multirow[t]{3}{*}{$m / z$} & $R S E$ & $S E M$ & $R S E$ & SEM & RSE & $S E M$ \\
\hline & & \multirow[t]{2}{*}{ Striatum } & \multirow[t]{2}{*}{ Striatum } & \multirow{2}{*}{$\begin{array}{l}\text { Corpus } \\
\text { Callosum }\end{array}$} & \multirow{2}{*}{$\begin{array}{l}\text { Corpus } \\
\text { Callosum }\end{array}$} & \multirow{2}{*}{$\begin{array}{l}\text { Cerebral } \\
\text { Cortex }\end{array}$} & \multirow{2}{*}{$\begin{array}{l}\text { Cerebral } \\
\text { Cortex }\end{array}$} \\
\hline & & & & & & & \\
\hline GM3 C18 & 1180.4 & 1.0 & 0.11 & 1.3 & 0.09 & 0.8 & 0.07 \\
\hline GM2 C18 & 1383.5 & 1.0 & 0.11 & 0.9 & 0.07 & 0.8 & 0.12 \\
\hline GM2 C2O & 1411.6 & 1.2 & 0.29 & 0.8 & 0.04 & 0.8 & 0.11 \\
\hline$G D 3 C 18(K+)$ & 1511.6 & 2.4 & 0.31 & 1.3 & 0.10 & 1.8 & 0.34 \\
\hline GM1 C18 & 1545.7 & 2.2 & 0.33 & 2.5 & 0.75 & 2.8 & 0.33 \\
\hline GMI C2O & 1573.7 & 2.9 & 0.49 & 2.2 & 0.50 & 3.1 & 0.55 \\
\hline$G D 2 C 16(K+)$ & 1686.0 & 1.9 & 0.30 & $\mathrm{n} / \mathrm{a}$ & $\mathrm{n} / \mathrm{a}$ & 1.4 & 0.33 \\
\hline$G D 2 C 18(K+)$ & 1715.7 & 1.7 & 0.66 & $\mathrm{n} / \mathrm{a}$ & $\mathrm{n} / \mathrm{a}$ & 1.9 & 0.98 \\
\hline GT3 C20 & 1792.8 & $14.9^{*}$ & 5.96 & 2.6 & 0.38 & 14.7 & 8.70 \\
\hline GT3 C22 & 1820.9 & 7.8 & 2.49 & 1.6 & 0.31 & 7.1 & 3.68 \\
\hline GD1 C18 & 1837.2 & 2.9 & 0.35 & 1.4 & 0.28 & 3.1 & 0.44 \\
\hline
\end{tabular}

Table 1. The effect of AF wash on the MALDI-IMS signals of gangliosides in fresh frozen rat brain tissue. Ratio of signal enhancement (RSE) and standard error mean (SEM) from the striatum, corpus callosum and cerebral cortex regions of fresh frozen rat brain tissue sections due to washing with ammonium formate. ${ }^{*}$ GT3 C20 showed an abnormally high enhancement ratio due to its minimal presence in unwashed samples, thus the ratio observed may not be representative of the actual signal enhancement. 


\subsection{MALDI-IMS of gangliosides in formalin fixed tissue}

We next aimed to assess the effects of the aqueous wash on post-fixed rat brain tissue sections, a similar fixation method to the storage of human tissue used for clinical studies. MALDI-IMS images obtained from formalin post-fixed rat brain tissue sections, with and without AF wash, showed the expected signal intensity enhancement and similar spatial resolutions. The spectra obtained from formalin post-fixed tissue was similar to those obtained from fresh frozen tissue, showing an increase in lipid signal while retaining a low signal to noise ratio (Figure 6B). The mass spectra of the striatum region (dotted circle in Figure 6A) obtained showed a significant increase in signal for the total spectrum of AF washed tissue (Figure 6B) as well as for the individual GM1 peaks (Figure 6C) while maintaining a similar signal to noise ratio as the unwashed tissue. Quantification of GM1 species show a statistically significant increase in both d18:1 and d20:1 species in the AF washed rat brain tissue sections ( $p<0.05$, Figure 6D). As with the fresh frozen rat tissue samples, similar increases in ganglioside signal were observed in white matter specific regions, such as the corpus callosum (Red Dot in Figure 6A, Figure 6E-F), and grey matter specific regions, such as the cerebral cortex (Blue Dot in Figure 6A, Figure 6H-J). The changes in signal intensities for other gangliosides appearing within the spectrum are outlined in Table 2. 

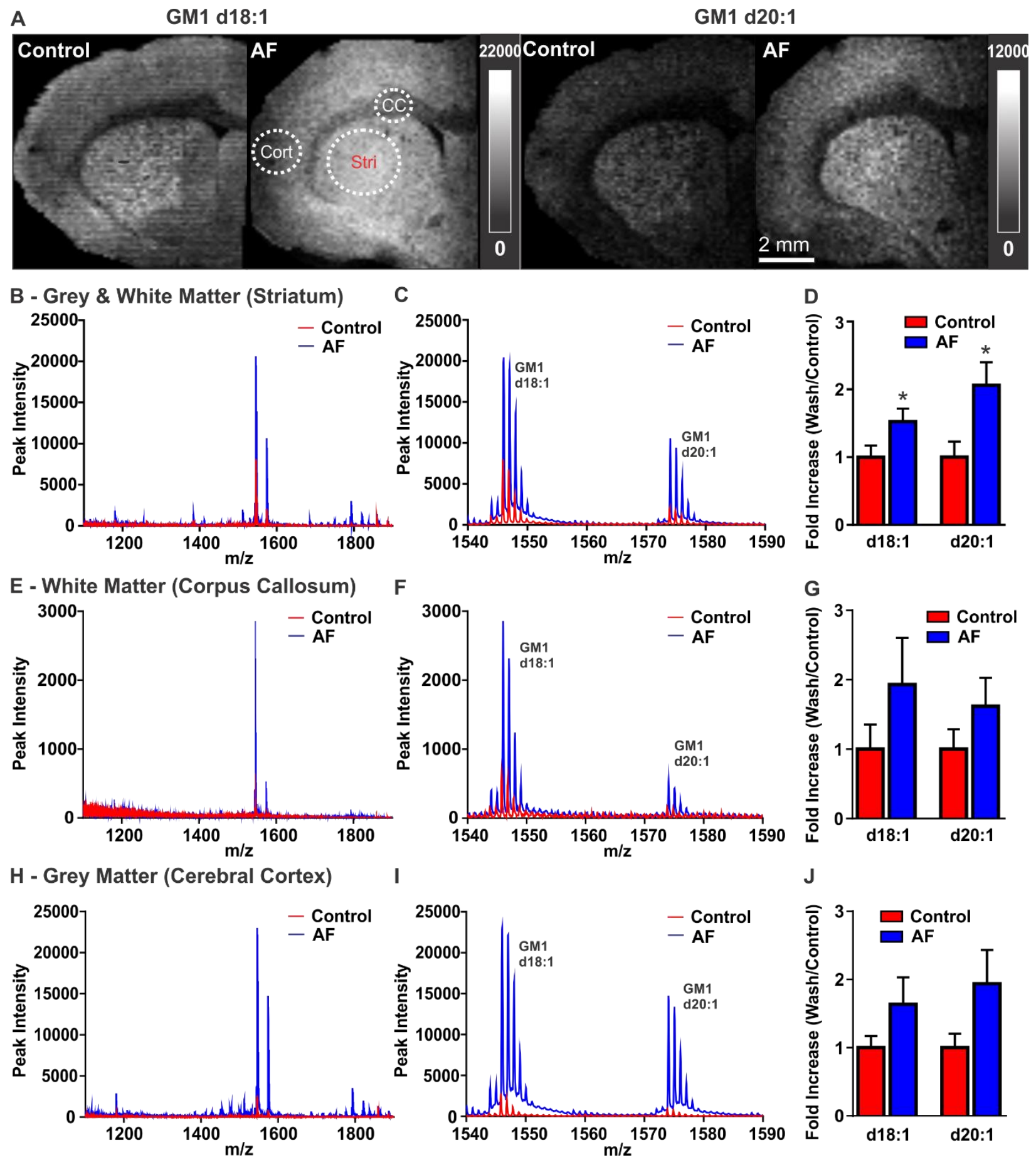

Figure 6. The effect of AF wash on the MALDI-IMS signals of gangliosides in formalin post-

fixed rat brain tissue. A comparison of ganglioside GM1 detection in the white and grey matter areas of post-fixed rat brain tissue from control and AF washed samples. Signal enhancement is 
observed from the mass spectra and degree of signal enhancement can be seen through a comparative area under curve analysis of GM1. (A) MALDI-IMS generated intensity maps of GM1 d18:1 and d20:1 from control and AF washed formalin post-fixed rat brain tissue. Striatum, corpus callosum and cortex regions of the brain labelled with a dotted white circle, a red dot and blue dot respectively. (B) Mass spectra of gangliosides and other lipids from the striatum (dotted circles in A). (C) Mass spectra of GM1 d18:1 and d20:1 from the striatum (D) Quantification of GM1 d18:1 and d20:1 species in the striatum. (E) Mass spectra of gangliosides and other lipids from the corpus callosum. (F) Mass spectra of GM1 d18:1 and d20:1 from the corpus callosum (G) Quantification of GM1 d18:1 and d20:1 species in the corpus callosum. (H) Mass spectra of gangliosides and other lipids from the cerebral cortex. (I) Mass spectra of GM1 d18:1 and d20:1 from the cerebral cortex. (J) Quantification of GM1 d18:1 and d20:1 species in the cerebral cortex. * indicates statistical significance, Student's t-test, $\mathrm{p}<0.05, \mathrm{n}=5$ for each experimental group. 


\begin{tabular}{|c|c|c|c|c|c|c|c|}
\hline Molecular & $m / z$ & $R S E$ & SEM & $R S E$ & SEM & $R S E$ & SEM \\
\hline \multirow[t]{2}{*}{ Identity } & & Striatum & Striatum & Corpus & Corpus & Cerebral & Cerebral \\
\hline & & & & Callosum & Callosum & Cortex & Cortex \\
\hline GM3 C18 & 1180.4 & 1.2 & 0.09 & 1.2 & 0.19 & 1.1 & 0.16 \\
\hline GM2 C18 & 1383.5 & 1.0 & 0.04 & 1.2 & 0.39 & 0.8 & 0.07 \\
\hline GM2 C20 & 1411.6 & 1.0 & 0.08 & 0.8 & 0.12 & 0.8 & 0.10 \\
\hline GD3 C18 $(K+)$ & 1511.6 & 2.0 & 0.17 & 2.1 & 0.23 & 1.3 & 0.09 \\
\hline GM1 C18 & 1545.7 & 1.5 & 0.19 & 1.9 & 0.67 & 1.6 & 0.39 \\
\hline GM1 C20 & 1573.7 & 2.0 & 0.33 & 1.6 & 0.41 & 1.9 & 0.49 \\
\hline$G D 2 C 16(K+)$ & 1686.0 & 1.6 & 0.16 & 1.0 & 0.15 & 1.1 & 0.16 \\
\hline$G D 2 C 18(K+)$ & 1715.7 & 0.9 & 0.10 & 0.8 & 0.13 & 0.9 & 0.10 \\
\hline GT3 C20 & 1792.8 & 4.0 & 0.73 & 2.3 & 0.49 & 3.7 & 1.42 \\
\hline GT3 C22 & 1820.9 & 3.5 & 0.62 & 2.2 & 0.51 & 3.7 & 1.20 \\
\hline GD1 C18 & 1837.2 & 2.9 & 0.53 & 1.7 & 0.29 & 2.7 & 0.43 \\
\hline
\end{tabular}

Table 2. The effect of AF wash on the MALDI-IMS signals of gangliosides in formalin postfixed rat brain tissue. Ratio of signal enhancement (RSE) and standard error mean (SEM) from the striatum, corpus callosum and cerebral cortex regions of post-fixed rat brain tissue sections obtained from an area under curve comparison of control to AF washed tissue. 


\subsection{MALDI-IMS of formalin post-fixed human brain tissue}

We next aimed to assess the potential for the AF wash to enhance MALDI-IMS signal in human brain tissue that had been post-fixed in formalin and stored in formalin for various lengths of time, up to 15 years (Figure 7). Cerebral cortex comprising both white matter and grey matter was chosen and MALDI-IMS images were acquired from control and AF washed tissue (Figure 7A). AF washed human brain tissue showed a greater overall signal in the mass spectrum in both the grey matter (Figure 7B) and white matter (Figure 7E) of the cerebral cortex. The cortical white matter in human tissue contained significantly more lipid molecules than the grey matter of the brain, however GM1 was significantly more abundant the grey matter. AF wash significantly increased GM1 signal in both grey matter (Figure 7C) and white matter (Figure 7F). Quantification of GM1 signals revealed a significant increase in d18:1 and d20:1 signal in the grey matter (Figure 7D) and significant increase in d18:1 signal in the white matter (Figure 7G) of AF washed tissue compared to controls $(\mathrm{p}<0.05)$. Signal enhancement of other prominent gangliosides is shown in Table 3. Confirmation of GM1 d:18 and d:20 molecular identity was obtained through the use of MS/MS comparing the characteristic peaks obtained from rat and human samples to ensure that the same molecule was being detected in each case. (Figure 8). 

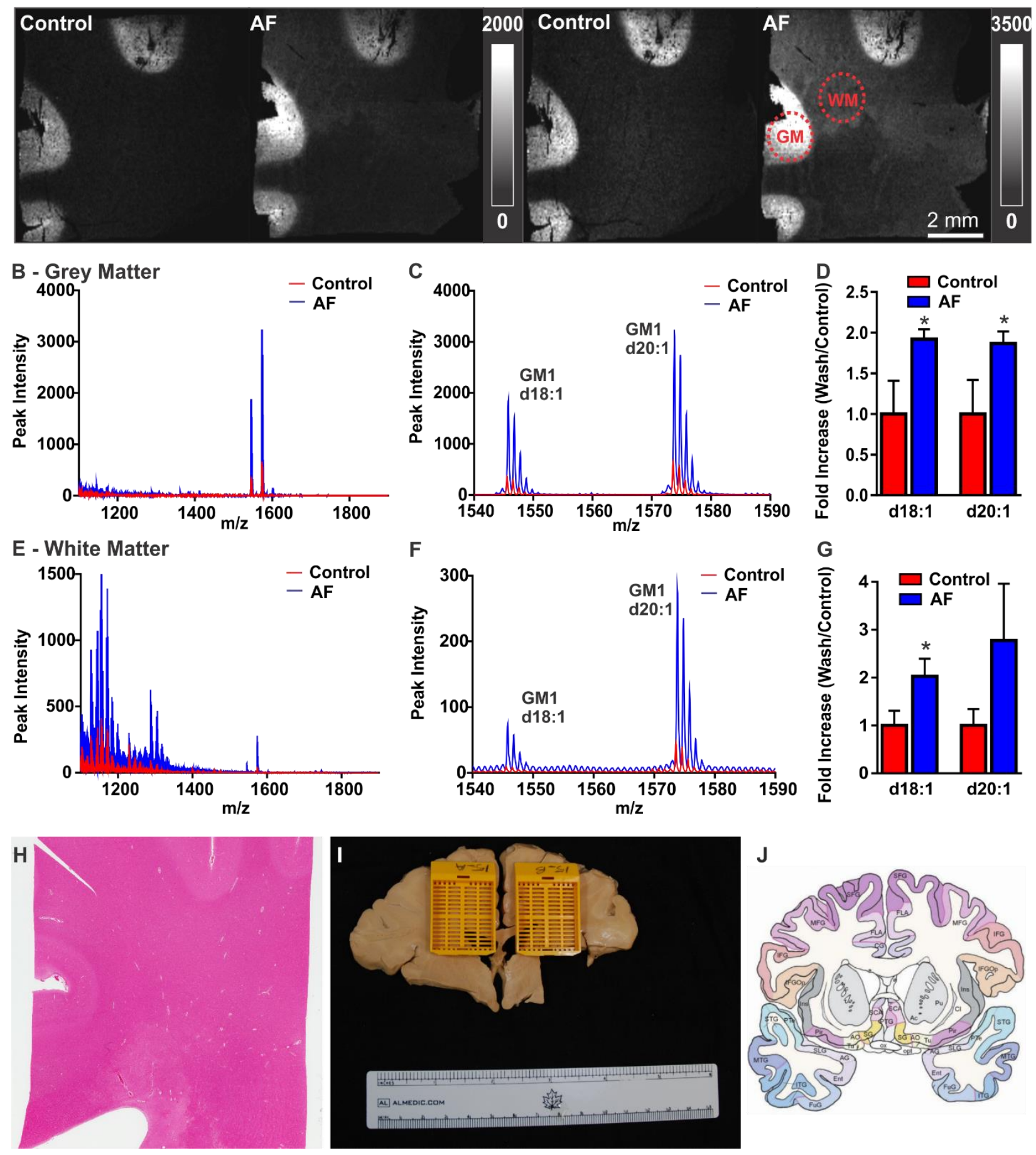

Figure 7. The effect of AF wash on the MALDI-IMS signals of gangliosides in formalin post-

fixed human brain tissue. A comparison of ganglioside GM1 detection in the white and grey matter areas of fixed human brain tissue from control and AF washed samples. Signal 
enhancement is observed from the mass spectra and degree of signal enhancement can be seen through a comparative area under curve analysis of GM1. (A) MALDI-IMS generated intensity maps of GM1 d18:1 and d20:1 from control and AF washed formalin post-fixed human cerebral cortical brain tissue. Mass spectra of gangliosides and other lipids from the human cerebral cortical (B) grey matter and (E) white matter (outlined in A: GM-grey matter; WM-white matter). Mass spectra of GM1 d18:1 and d20:1 from the cortical (C) grey matter and (F) white matter. (D) Quantification of GM1 d18:1 and d20:1 species in cortical grey matter and (G) white matter * indicates statistical significance, Student's t-test, $\mathrm{p}<0.05, \mathrm{n}=5$ for each experimental group. $(\mathrm{H})$ Hematoxylin and eosin stain of tissue block visualized in A \& B. (I) Area tissue blocks were taken from human brain tissue. (J) Atlas image of associated brain region of tissue blocks depicting anatomical landmarks present in sections (100). 


\begin{tabular}{l|lll}
$\begin{array}{l}\text { Molecular Identity } \\
\text { (Grey Matter) }\end{array}$ & $\boldsymbol{m} / \boldsymbol{z}$ & $\boldsymbol{R S E}$ & SEM \\
\hline GM3 C18 & & & \\
GM2 C18 & 1180.4 & 1.0 & 0.19 \\
GM2 C20 & 1383.5 & 1.3 & 0.12 \\
GM1 C18 & 1411.6 & 1.3 & 0.16 \\
GM1 C20 & 1545.7 & 1.9 & 0.12 \\
GM1 C22 & 1573.7 & 1.9 & 0.15 \\
& 1601.8 & 2.2 & 0.46 \\
Molecular Identity & $\boldsymbol{m} / z$ & $\boldsymbol{R S E}$ & SEM \\
(White Matter) & & & \\
\hline GM1 C18 & 1545.7 & 2.0 & 0.36 \\
GM1 C20 & 1573.7 & 2.8 & 1.2
\end{tabular}

Table 3. The effect of AF wash on the MALDI-IMS signals of gangliosides in formalin fixed human brain tissue. Ratio of signal enhancement (RSE) and standard error mean (SEM) from the cortical grey matter of formalin fixed human brain tissue sections obtained from an area under curve comparison of control to AF washed samples. 
A. GM1 d18:1 Rat

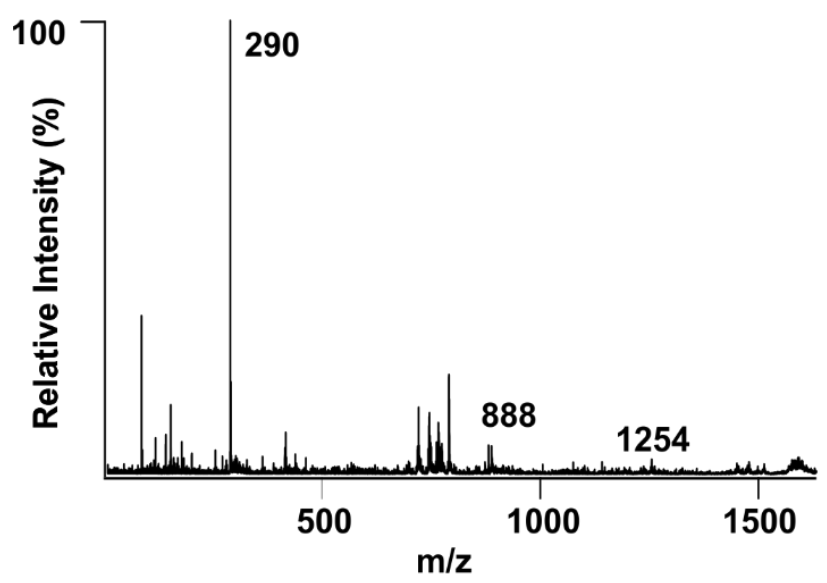

\section{GM1 d20:1 Rat}

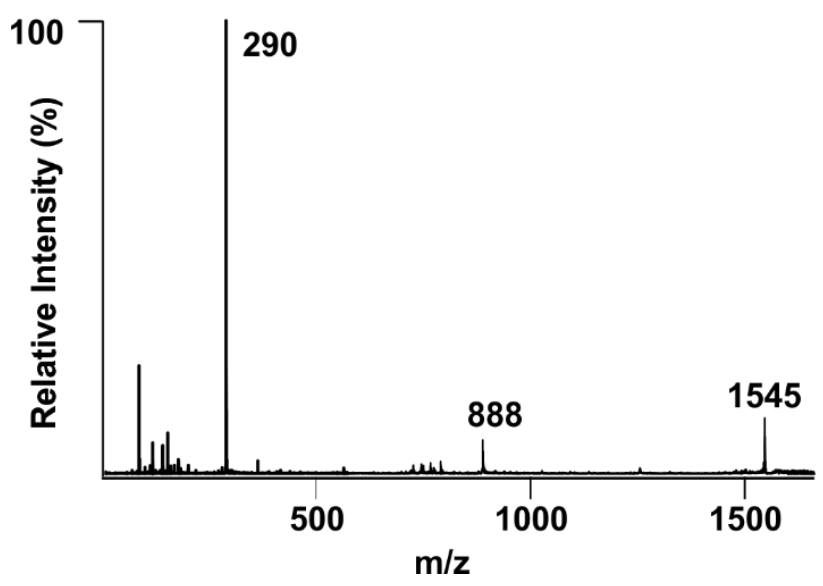

B. GM1 d18:1 Human

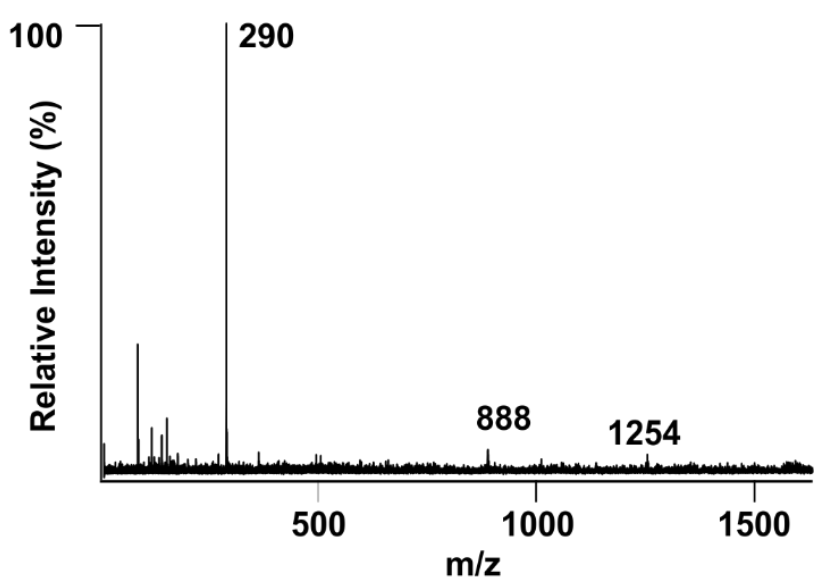

D. GM1 d20:1 Human

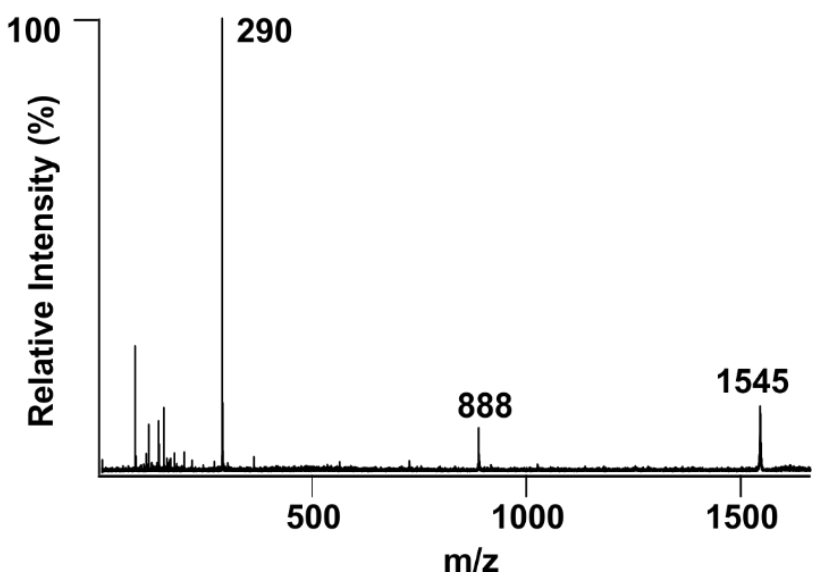

Figure 8. On-tissue negative mode MS/MS identification of the major ganglioside species. Comparison of ganglioside species detected from rat and human samples confirms that the same ganglioside species are being detected in each case. A. GM1 d18:1 (m/z 1545) obtained from rat brain tissue; B. GM1 d18:1 (m/z 1545) obtained from human brain tissue C. GM1 d20:1 (m/z 1573) obtained from rat brain tissue; D. GM1 d20:1 (m/z 1573) obtained from human brain tissue. MS/MS spectra produced the diagnostic fragmentation ions which corresponded to the data previously reported [41]. Generally, fragmentation confirmed that sialic acid produced an intense 
peak at m/z 290 with additional characteristic fragmentation of various sugar units (m/z 564, 727, and/or 888). Characterization of gangliosides was performed on-tissue using a SCIEX 5800 MALDI TOF-TOF mass spectrometer. DAN matrix was applied onto tissue sections by sublimation and negative ion MS/MS spectra were acquired. The detector multiplier voltage was maximized at $2.25 \mathrm{kV}$ and a total of 900 shots per spectrum was acquired in a continuous stage motion. Following the external calibration at $\pm 50 \mathrm{ppm}$ mass tolerance, the precursor ion was isolated within an $\mathrm{m} / \mathrm{z}$ window of 40 full width at half maximum (FWHM) resolution and fragmented in a posts-source decay mechanism. MS/MS mode experiments were conducted using 10 to $20 \%$ higher laser energy compared to the MS mode, in order to promote fragmentation of the analytes of interest for structural identification. 


\subsection{Comparison of Fresh Frozen and Formalin Fixed MALDI-IMS}

Following the assessment of the AF wash on each tissue type, a side by side comparison of fresh frozen and formalin fixed tissues is shown in Table 4 showing the ratio of signal enhancement of the prominent gangliosides detected in each tissue type. Focusing on GM1 as the example, fresh frozen tissue is observed to have a higher degree of signal enhancement following an AF wash compared to formalin fixed tissue in both rat and human. When comparing formalin fixed samples of rat and human brain samples, both show similar degrees of signal enhancement of a 2-fold increase. 


\begin{tabular}{|c|c|c|c|c|}
\hline & & $R S E$ & $R S E$ & \multirow{2}{*}{$\begin{array}{l}\text { RSE } \\
\text { (Fresh Frozen Rat }\end{array}$} \\
\hline Molecular & & (Fixed Human & (Fixed Rat & \\
\hline Identity & $m / z$ & Grey Matter) & Grey Matter) & Grey Matter) \\
\hline GM3 C18 & 1180.4 & 1.0 & 1.1 & 0.8 \\
\hline GM2 C18 & 1383.5 & 1.3 & 0.8 & 0.8 \\
\hline GM2 C2O & 1411.6 & 1.3 & 0.8 & 0.8 \\
\hline GM1 C18 & 1545.7 & 1.9 & 1.6 & 2.8 \\
\hline \multirow[t]{2}{*}{ GM1 C20 } & 1573.7 & 1.9 & 1.9 & 3.1 \\
\hline & & RSE & RSE & RSE \\
\hline Molecular & & (Fixed Human & (Fixed Rat & (Fresh Frozen Rat \\
\hline Identity & $\mathbf{m} / \mathbf{z}$ & White Matter) & White Matter) & White Matter) \\
\hline GM1 C18 & 1545.7 & 2.0 & 1.9 & 2.5 \\
\hline GM1 C20 & 1573.7 & 2.8 & 1.6 & 2.2 \\
\hline
\end{tabular}

Table 4. Side by side comparison of degree of signal enhancement from all types of tissue tested. Ratio of signal enhancement (RSE) from fresh frozen and post-fixed rat brain tissue and from post-fixed human tissue obtained from an area under curve comparison of control to AF washed samples. 


\section{Chapter 4: Discussion}

The main objective of this study was to establish a method of detecting and imaging gangliosides from formalin fixed tissue in negative ion mode MALDI IMS, for the clinical applicability and reproducibility of formalin fixed tissue imaging. This was accomplished utilizing an aqueous wash of AF, previously shown to increase signal in MALDI IMS $(80,83)$. To our knowledge, this is the first time that gangliosides have been visualized in formalin fixed clinical brain samples utilizing MALDI-IMS. The intensity maps generated for d18:1 and d20:1 species of ganglioside GM1 show a significant increase in signal on all tissues tested while retaining the spatial distribution of the molecules within the tissue section. This demonstrates that an aqueous wash with AF is a method of signal enhancement applicable to multiple types of tissue analyzed by MALDI-IMS.

Spectra generated from the analyzed tissue sections further demonstrated the ability of the AF wash to enhance ganglioside signals within tissue sections. The spectra were focused to the GM1 species present in the tissue to compare pre and post washed sections for further evaluation and a comparative analysis showed a 3-fold increase for fresh frozen tissue and an approximately 2-fold increase for post-fixed tissue samples. Results indicate that immersion in formalin does have a detrimental effect on the amount of lipids that remain in tissue post-fixation as the fresh frozen and post-fixed brain sections were obtained from the same animal but the degree of signal enhancement was a not as high in fixed tissue as it was in the frozen tissue. However, upon comparison of signal from formalin fixed rat brain samples that had been post-fixed in formalin for 15 minutes and human brain tissue samples that had remained in formalin up to 15 years, a similar degree of signal enhancement is observed, indicating that the length of time tissue samples 
are immersed in formalin may not affect the lipids within the samples to the extent that was previously believed.

MALDI IMS, although an effective technique, is not without its limitations. One of the limitations is that each mass spectrum obtained from individual images is unique in signal intensity and signal to noise ratio based on minute differences in the sample preparation, matrix application, variations within the tissue itself and various other inevitable variables (101). In the present work, these variables were accounted for by performing experiments of washed and control tissue at the same time and under the same conditions for a comparative analysis rather than absolute quantification, removing sample-to-sample variation as much as possible. An additional limitation of GM1 quantification using MALDI IMS is the potential of sialic acid loss from polysialated ganglioside species such as GD1 and GT3, also detected in the present experiment, which can increase the observed signal of monosialylated GM1 (102).

The results of this study give way to many avenues for future research. Previous research that has only looked at profiled various lipids and other molecules within formalin fixed tissue up to this point can be expanded upon. For example, the study performed by de la Monte et. al. (67) profiled many lipids, including sphingolipids such as gangliosides, in the white matter of human alcoholics to assess the lipid changes associated with alcoholism. Utilizing an aqueous wash method, brain sections from alcoholics and non-alcoholics could be imaged and the spatial distribution of the lipids examined, providing more information on the distribution of these changes throughout the brain and with higher sensitivity. The same is true for studies that have studied formalin fixed cancerous tissue through lipid profiling $(65,66)$. By examining clinical sections of cancerous tumors and surrounding tissue, a deeper understanding of the lipid changes occurring as a result of tumor growth could be obtained. It is also possible that lipids previously 
in too low of a quantity to be detected could be detected in clinical tissue through the use of an aqueous wash, further expanding changes observed within these studies.

Imaging of formalin fixed brain tissue in particular will allow for further studies of clinical brain samples diagnosed with a neurodegenerative disease that have been kept in storage for extended periods of time. One such avenue is in tissue diagnosed with Alzheimer's disease, both early and late stage diseased samples. An indicator of Alzheimer's disease is the appearance of brain lesions as white, hyperintense areas within MRI images of the brain, also known as white matter hyperintensities. By locating the areas with white matter hyperintensities in clinical samples and blocking them for sectioning, it would allow for the study the changes occurring within these lesions compared to normal appearing white matter in the MRI. If molecular changes can be identified specific to the hyperintense regions, it could give direction to possible therapeutic pre-treatment methods for Alzheimer's disease.

Although ganglioside GM1 was selected for the focus of these studies to show imaging of lipids is possible in formalin fixed clinical brain tissue, exploring the potential of imaging other lipids, proteins or peptides in fixed tissue utilizing an aqueous wash is an avenue that should be explored. Imaging of proteins has been performed in pre-clinical tissue $(68,69)$ but to our knowledge has yet to be performed in clinical brain tissue. It may be possible to image some proteins after fixation if their signal can be enhanced which could offer more avenues for study. This also prompts the study of other aqueous buffers to be tested for the possibility that they pay have preferential interactions with specific molecules allowing for the detection and study of those molecules in MALDI IMS.

Lastly, though the exact mechanism of enhancement caused by the aqueous wash is unknown, it does appear to be independent of the matrix used for MALDI analysis as DAN was 
used in these studies and DHB has been utilized in literature (80) with tissue washed with an aqueous buffer. Studies have also examined the effectiveness of molecular signal enhancement via an aqueous wash in ESI (83), but as of yet an ESI has not used this method for imaging formalin fixed brain tissue. A comparative study of fixed clinical tissue between MALDI and ESI would determine the consistency of the wash method across multiple platforms and possible show differing molecules based on the method of molecular ionization. 


\section{Conclusions}

In summary, MALDI IMS is a viable and effective method of analyzing gangliosides from formalin fixed tissue samples through the use of an ammonium formate wash to enhance the signal from obtained from the tissue samples. When compared to control tissue, an AF wash yields a 2to 3-fold increase in overall spectra signal while retaining a relatively low signal to noise ratio and maintaining spatial distribution of molecules within the samples. Visualization of analyte molecules was qualitatively improved in the AF washed images compared to the control images. These results are promising for future analysis and visualization of formalin fixed clinical samples, as well as for the future understanding of neurodegenerative diseases utilizing MALDI-IMS. 


\section{References}

(1) Downward, K. (2007) Mass Spectrometry: A Foundation Course. Royal Society of Chemistry

(2) Mark T.D.; Dunn G. H. (2013) Electron Impact Ionization. Springer Science \& Business Media

(3) Ho, C. S.; Chan, M. H. M.; Cheung, R. C. K.; Law, L. K.; Lit L. C. W.; Ng, K. F.; Suen, M. W. M.; Tai HL. Electrospray Ionisation Mass Spectrometry: Principles and Clinical Applications. Clin Biochem Rev. 24 (1) 3-12 (2003)

(4) Syed SU, Maher S, Taylor S. Quadrupole mass filter operation under the influence of magnetic field. J. of Mass Spec. 48 (12): 1325-1339 (2013)

(5) Weickhardt, C.; Moritz, F.; Grotemeyer, J. Time-of-Flight Mass Spectrometry: Stateof-the-Art in Chemical Analysis and Molecular Science. Mass Spectrometry Reviews. 15, 139- $162(1996)$

(6) Hu Q, Noll RJ, Li H, Makarov A, Hardman M, Graham Cooks R. The Orbitrap: a new mass spectrometer. J.of Mass Spec. 40 (4) 430-43 (2005)

(7) Hunt, N. J.; Phillips, L.; Waters, K. A.; Machaalani, R. Proteomic MALDI-TOF/TOFIMS Examination of Peptide Expression in the Formalin Fixed Brainstem and Changes in Sudden Infant Death Syndrome Infants. J. Proteomics. 138, 48-60 (2016)

(8) McDonnell, L. A.; Corthals, G. L.; Willems, S. M.; van Remoortere, A.; van Zeijl, R. J. M.; Deelder, A. M. Peptide and Protein Imaging Mass Spectrometry in Cancer Research. J. Proteomics. 73 (10), 1921-1944 (2010) 
(9) OuYang, C.; Liang, Z.; Li, L. Mass Spectrometric Analysis of Spatio-Temporal Dynamics of Crustacean Neuropeptides. Biochim. Biophys. Acta - Proteins Proteomics. 1854 (7), 798-811. (2015)

(10) Weishaupt, N.; Caughlin, S.; Yeung, K. K.; Whitehead, S. N.; Whitehead, S. N. Differential Anatomical Expression of Ganglioside GM1 Species Containing D18 : 1 or D20 : 1 Sphingosine Detected by MALDI Imaging Mass Spectrometry in Mature Rat Brain. Front Neuroanat. 9, 1-11 (2015)

(11) Sun, N.; Fernandez, I. E.; Wei, M.; Wu, Y.; Aichler, M.; Eickelberg, O.; Walch, A. Pharmacokinetic and Pharmacometabolomic Study of Pirfenidone in Normal Mouse Tissues Using High Mass Resolution MALDI-FTICR-Mass Spectrometry Imaging. Histochem. Cell Biol. 145 (2), 201-211 (2016)

(12) Markides, K.; Gräslund, A. Advanced information on the Nobel Prize in Chemistry 2002. The Royal Swedish Academy of Sciences. 1-13 (2002)

(13) Karas, M.; Hillenkamp, F. Laser desorption ionization of proteins with molecular masses exceeding 10,000 daltons. Anal. Chem. 60 (20), 2299-301 (1998)

(14) Karas, M.; Bahr, U. Laser Desorption Ionization Mass Spectrometry of Large Biomolecules. Trends in Anal. Chem. 9 (10), 321-5 (1990)

(15) Caprioli, R. M.; Farmer, T. B.; Gile. Molecular Imaging of Biological Samples: Localization of Peptides and Proteins Using MALDI-TOF MS. J. Anal. Chem. 69 (23), $4751-4760$ (1997)

(16) Stoeckli, M.; Chaurand, P.; Hallahan, D. E.; Caprioli, R. M. Imaging mass spectrometry: A new technology for the analysis of protein expression in mammalian tissues Nat. Med. (7) 493-496 (2001) 
(17) McDonnell, L. A.; Heeren, R. M. A. Imaging mass spectrometry Mass Spectrom. Rev. 26 (4) 606-643 (2007)

(18) Chughtai, K.; Heeren, R. M. A. Mass Spectrometric Imaging for Biomedical Tissue Analysis Chem. Rev. 110 (5) 3237-3277 (2010)

(19) Amstalden, v. H. E. R.; Smith, D. F.; Heeren, R. M. A. A concise review of mass spectrometry imaging. J. Chromatogr., A 1217 (25) 3946-3954 (2010)

(20) Cornett, D. S.; Reyzer, M. L.; Chaurand, P.; Caprioli, R. M. MALDI imaging mass spectrometry: molecular snapshots of biochemical systems. Nat. Methods (4) 828-833 (2007)

(21) Pacholski, M. L.; Winograd, N. Imaging with Mass Spectrometry. Chem. Rev. 99 (10) 2977-3006 (1999)

(22) Liebl, H. Ion Microprobe Mass Analyzer J. Appl. Phys. 38, 5277 (1967)

(23) Wiseman, J. M., \& Laughlin, B. C. Desorption Electrospray Ionization (DESI) Mass Spectrometry: Current Separations and Drug Development, 11-14 (2005)

(24) Spengler, B.; Hubert, M. Scanning microprobe matrix-assisted laser desorption ionization (SMALDI) mass spectrometry: Instrumentation for sub-micrometer resolved LDI and MALDI surface analysis. J. Am. Soc. Mass Spectrom. 13 (6) 735$748(2002)$

(25) Norris, J. L.; Caprioli, R. M. Analysis of tissue specimens by matrix-assisted laser desorption/ionization imaging mass spectrometry in biological and clinical research. Chem. Rev. 113 (4) 2309-2342 (2013)

(26) Cornett, D. S.; Mobley, J. A.; Dias, E. C.; Andersson, M.; Arteaga, C. L.; Sanders, M. E.; Caprioli, R. M. A Novel Histology-directed Strategy for MALDI-MS Tissue 
Profiling That Improves Throughput and Cellular Specificity in Human Breast Cancer. Mol. Cell. Proteomics 5 (10) 1975-1983 (2006)

(27) Axt, J.; Murphy, A. J.; Seeley, E. H.; Martin, C. A.; Taylor, C.; Pierce, J.; Caprioli, R. M.; Whiteside, M.; Lovvorn, H. N., III. Race Disparities in Wilms Tumor Incidence and Biology. J. Surg. Res. 170 (1) 112-119 (2011)

(28) Lazova, R.; Seeley, E. H.; Keenan, M.; Gueorguieva, R.; Caprioli, R. M. Imaging Mass Spectrometry - a new and promising method to differentiate Spitz nevi from Spitzoid malignant melanomas. Am. J. Dermatopathol. 34 (1) $82-90$ (2012)

(29) Oswald-Richter, K. A.; Beachboard, D. C.; Seeley, E. H.; Abraham, S.; Shepherd, B. E.; Jenkins, C. A.; Culver, D. A.; Caprioli, R. M.; Drake, W. P. Dual Analysis for Mycobacteria and Propionibacteria in Sarcoidosis BAL. J. Clin. Immunol. 32 (5) 1129$1140(2012)$

(30) Burnum, K. E.; Tranguch, S.; Mi, D.; Daikoku, T.; Dey, S. K.; Caprioli, R. M. Endocrinol. Imaging Mass Spectrometry Reveals Unique Protein Profiles during Embryo Implantation. Endocrinology. 149 (7) 3274-3278 (2008)

(31) Casadonte, R.; Caprioli, R. M. Proteomic analysis of formalin-fixed paraffin-embedded tissue by MALDI imaging mass spectrometry. Nat. Protoc. 6, 1695-1709 (2011)

(32) Groseclose, M. R.; Andersson, M.; Hardesty, W. M.; Caprioli, R. M. Identification of proteins directly from tissue: in situ tryptic digestions coupled with imaging mass spectrometry. J. Mass Spectrom. 42 (2) 254-262 (2007)

(33) Groseclose, M. R.; Massion, P. P.; Chaurand, P.; Caprioli, R. M. High-throughput proteomic analysis of formalin-fixed paraffin-embedded tissue microarrays using MALDI imaging mass spectrometry. Proteomics. 8 (18) 3715-3724 (2008) 
(34) Hardesty, W. M.; Kelley, M. C.; Mi, D.-M.; Low, R. L.; Caprioli, R. M. Protein signatures for survival and recurrence in metastatic melanoma. J. Proteomics. 74 (7) $1002-1014(2011)$

(35) Taverna, D.; Nanney, L. B.; Pollins, A. C.; Sindona, G.; Caprioli, R. Spatial mapping by imaging mass spectrometry offers advancements for rapid definition of human skin proteomic signatures. Exp. Dermatol. 20 (8) 642-647 (2011)

(36) Chaurand, P. Imaging mass spectrometry of thin tissue sections: a decade of collective efforts. J. of Proteomics. 75 (16) 4883-92 (2012)

(37) Schwartz, S. A.; Reyzer, M. L.; Caprioli, R. M. Direct tissue analysis using matrixassisted laser desorption/ionization mass spectrometry: practical aspects of sample preparation. J. Mass Spectrom. 38 (7) 699-708 (2003)

(38) Crecelius, A. C.; Cornett, D. S.; Caprioli, R. M.; Williams, B.; Dawant, B. M.; Bodenheimer, B. Three-dimensional visualization of protein expression in mouse brain structures using imaging mass spectrometry. J. Am. Soc. Mass Spectrom. 16 (7) 1093$1099(2005)$

(39) Sugiura, Y., Shimma, S., Konishi, Y., Yamada, M. K., \& Setou, M. Imaging mass spectrometry technology and application on ganglioside study; visualization of age dependent accumulation of C20-ganglioside molecular species in the mouse hippocampus. PloS One, 3(9), e3232. (2008)

(40) Zaima, N., Hayasaka, T., Goto-Inoue, N., \& Setou, M. Matrix-assisted laser desorption/ionization imaging mass spectrometry. Int. Mol. Sci. 11 (12) 5040-55 (2010) 
(41) Chaurand, P.; Schwartz, S. A.; Billheimer, D.; Xu, B. J.; Crecelius, A.; Caprioli, R. M. Integrating Histology and Imaging Mass Spectrometry. Anal. Chem. 76 (4) 1145-1155 (2004)

(42) Karas, M.; Kruger, R. Ion Formation in MALDI: The Cluster Ionization Mechanism. Chem. Rev. 103 (2) 427-440 (2003)

(43) Jaskolla, T. W.; Karas, M. Compelling Evidence for Lucky Survivor and Gas Phase Protonation: The Unified MALDI Analyte Protonation Mechanism. J. Am. Soc. Mass Spectrom. 22 (6) 976-988 (2011)

(44) Strupat, K.; Karas, M.; Hillenkamp, F. 2,5-Dihydroxybenzoic acid: a new matrix for laser desorption—ionization mass spectrometry. Int. J. Mass Spectrom. 111 (16) 89$102(1991)$

(45) Tholey, A.; Heinzle, E. Ionic (liquid) matrices for matrix-assisted laser desorption/ionization mass spectrometry—applications and perspectives. Anal. Bioanal. Chem. 386 (1) 24-37 (2006)

(46) Beavis, R. C.; Chait, B. T. Beavis, R. C.; Chait, B. T. Rapid Commun. Mass Spectrom. 1989, 3, 436. Rapid Commun. Mass Spectrom. 3 (12) 436-439 (1989)

(47) Thomas, A.; Charbonneau, J. L.; Fournaise, E.; Chaurand, P. Sublimation of New Matrix Candidates for High Spatial Resolution Imaging Mass Spectrometry of Lipids: Enhanced Information in Both Positive and Negative Polarities after 1,5Diaminonapthalene Deposition. Anal. Chem. 84 (4) 2048-2054 (2012)

(48) Caughlin, S.; Park, D. H.; Yeung, K. K.-C.; Cechetto, D. F.; Whitehead, S. N. Sublimation of DAN Matrix for the Detection and Visualization of Gangliosides in Rat Brain Tissue for MALDI Imaging Mass Spectrometry. J. Vis. Exp. (2017) 
(49) Chaurand, P., Stoeckli, M., and Caprioli, R. M. Direct profiling of proteins in biological tissue sections by MALDI mass spectrometry. Anal. Chem. 71, 5263- 5270 (1999)

(50) Schuerenberg, M.; Luebbert, C.; Deininger, S.; Mueller, R.; Suckau, D. J. P110-M A New Preparation technique for MALDI Tissue Imaging. Biomol. Tech. 2007, 18(1) 38 (2007)

(51) Zheng, Y.; Xu, Y.; Ye, B.; Lei, J.; Weinstein, M. H.; O’Leary, M. P.; Richie, J. P.; Mok, S. C.; Liu, B. C. Prostate carcinoma tissue proteomics for biomarker discovery. Cancer 98, 2576- $2582(2003)$

(52) Caldwell, R. L.; Caprioli, R. M. Tissue Profiling by Mass Spectrometry. Mol. Cell. Proteomics 4, 394-401 (2005)

(53) Hankin, J. A.; Barkley, R. M.; Murphy, R. C. Sublimation as a method of matrix application for mass spectrometric imaging. J. Am. Soc. Mass Spectrom. 18 (9) 16461652 (2007)

(54) Franzen, B.; Yang, Y.; Sunnemark, D.; Wickman, M.; Ottervald, J.; Oppermann, M.; Sandberg, K. Dihydropyrimidinase related protein-2 as a biomarker for temperature and time dependent post-mortem changes in the mouse brain proteome. Proteomics. 3 (10) 1920-1929 (2003)

(55) Ferrer, I.; Santpere, G.; Arzberger, T.; Bell, J.; Blanco, R.; Boluda, S.; Budka, H.; Carmona, M.; Giaccone, G.; Krebs, B.; Limido, L.; Parchi, P.; Puig, B.; Strammiello, R.; Strobel, T.; Kretzschmar, H. Brain Protein Preservation Largely Depends on the Postmortem Storage Temperature: Implications for Study of Proteins in Human Neurologic Diseases and Management of Brain Banks: A BrainNet Europe Study. J. Neuropathol. Exp. Neurol. 66 (1) 35-46 (2007) 
(56) Crecelius, A.; Gotz, A.; Arzberger, T.; Frohlich, T.; Arnold, G. J.; Ferrer, I.; Kretzschmar, H. A. Assessing quantitative post-mortem changes in the gray matter of the human frontal cortex proteome by 2-D DIGE. Proteomics 8 (6) 1276-1291 (2008)

(57) Skold, K.; Svensson, M.; Norrman, M.; Sjogren, B.; Svenningsson, P.; Andren, P. E. The significance of biochemical and molecular sample integrity in brain proteomics and peptidomics: Stathmin 2-20 and peptides as sample quality indicators. Proteomics. 7 (24) 4445-4456 (2007)

(58) Lemaire, R.; Wisztorski, M.; Desmons, A.; Tabet, J. C.; Day, R.; Salzet, M.; Fournier, I. MALDI-MS Direct Tissue Analysis of Proteins: Improving Signal Sensitivity Using Organic Treatments. Anal. Chem. 78 (20) 7145-7153 (2006)

(59) Fox, C. H.; Johnson, F. B.; Whiting, J.; Roller, P. P. The Journal of Histochemistry Formaldehyde Fixation Review Article. 33 (1985)

(60) Lemaire, R.; Desmons, A.; Tabet, J. C.; Day, R.; Salzet, M.; Fournier, I. Direct Analysis and MALDI Imaging of Formalin-Fixed, Paraffin-Embedded Tissue Sections. J. Proteome Res. 6 (4) 1295-1305 (2007)

(61) Metz, B.; Kersten, G. F.; Hoogerhout, P.; Brugghe, H. F.; Timmermans, H. A.; de Jong, A.; Meiring, H.; ten Hove, J.; Hennink, W. E.; Crommelin, D. J.; Jiskoot, W. Identification of Formaldehyde-induced Modifications in Proteins. J. Biol. Chem. 279, $6235-6243(2004)$

(62) Seeley, E. H.; Caprioli, R. M. MALDI Imaging Mass Spectrometry of Human Tissue: Method Challenges and Clinical Perspectives. Trends Biotechnol. 29 (3): 136-143 (2011) 
(63) Carter, C. L.; Mcleod, C. W.; Bunch, J. Imaging of Phospholipids in Formalin Fixed Rat Brain Sections by Matrix Assisted Laser Desorption/Ionization Mass Spectrometry. J. Am. Soc. Mass Spectrom. 22 (2011)

(64) Pietrowska, M.; Gawin, M.; Polańska, J.; Widłak, P. Tissue Fixed with Formalin and Processed without Paraffin Embedding Is Suitable for Imaging of Both Peptides and Lipids by MALDI-IMS. Proteomics (2016)

(65) Wojakowska, A.; Cole, L. M.; Chekan, M.; Bednarczyk, K.; Maksymiak, M.; OczkoWojciechowska, M.; Jarząb, B.; Clench, M. R.; Polańska, J.; Pietrowska, M.; et al. Discrimination of Papillary Thyroid Cancer from Non-Cancerous Thyroid Tissue Based on Lipid Profiling by Mass Spectrometry Imaging. Endokrynol. Pol. 69 (1), 2$8(2018)$

(66) Wang, X.; Deng, Z.; Huang, C.; Zhu, T.; Lou, J.; Wang, L.; Li, Y. Differential NGlycan Patterns Identified in Lung Adenocarcinoma by N- Glycan Profiling of Formalin-Fixed Paraffin-Embedded (FFPE) Tissue Sections. J. Proteomics. 172, 1-10 (2017)

(67) de la Monte, S. M.; Kay, J.; Yalcin, E. B.; Kril, J. J.; Sheedy, D.; Sutherland, G. T. Imaging Mass Spectrometry of Frontal White Matter Lipid Changes in Human Alcoholics. Alcohol. 67, 51-63 (2018)

(68) Vanickova, L.; Guran, R.; Kollár, S.; Emri, G.; Krizkova, S.; Do, T.; Heger, Z.; Zitka, O.; Adam, V. Mass Spectrometric Imaging of Cysteine Rich Proteins in Human Skin. Int. J. Biol. Macromol. 125, 270-277 (2019)

(69) Angel, P. M.; Comte-Walters, S.; Ball, L. E.; Talbot, K.; Mehta, A.; Brockbank, K. G.; Drake, R. R. Mapping Extracellular Matrix Proteins in Formalin-Fixed, Paraffin- 
Embedded Tissues by MALDI Imaging Mass Spectrometry. J. Proteome Res. 17, $635-646(2018)$

(70) Oetjen, J.; Lachmund, D.; Palmer, A.; Alexandrov, T.; Becker, M.; Boskamp, T.; Maass, P. An Approach to Optimize Sample Preparation for MALDI Imaging MS of FFPE Sections Using Fractional Factorial Design of Experiments. Anal. Bioanal. Chem. 408 (24), 6729-6740 (2016)

(71) Veloso, A.; Astigarraga, E.; Barreda-Gómez, G.; Manuel, I.; Ferrer, I.; Teresa Giralt, M.; Ochoa, B.; Fresnedo, O.; Rodríguez-Puertas, R.; Fernández, J. A. Anatomical Distribution of Lipids in Human Brain Cortex by Imaging Mass Spectrometry. J. Am. Soc. Mass Spectrom. 22 (2), 329-338 (2011)

(72) Veloso, A.; Fernández, R.; Astigarraga, E.; Barreda-Gómez, G.; Manuel, I.; Giralt, M. T.; Ferrer, I.; Ochoa, B.; Rodríguez-Puertas, R.; Fernández, J. A. Distribution of Lipids in Human Brain. Anal. Bioanal. Chem. 401 (1), 89-101 (2011)

(73) González de San Román, E.; Bidmon, H.-J.; Malisic, M.; Susnea, I.; Küppers, A.; Hübbers, R.; Wree, A.; Nischwitz, V.; Amunts, K.; Huesgen, P. F. Molecular Composition of the Human Primary Visual Cortex Profiled by Multimodal Mass Spectrometry Imaging. Brain Struct. Funct. 223 (6), 2767-2783 (2018)

(74) Anderson, D. M. G.; Spraggins, J. M.; Rose, K. L.; Schey, K. L. High Spatial Resolution Imaging Mass Spectrometry of Human Optic Nerve Lipids and Proteins. J. Am. Soc. Mass Spectrom. 26 (6), 940-947 (2015)

(75) Bornsen, K. O. Influence of Salts, Buffers, Detergents, Solvents, and Matrices on MALDI-MS Protein Analysis in Complex Mixtures. Methods Mol. Biol. 146, 387-404 (2000) 
(76) Goodwin, R. J.; Pennington, S. R.; Pitt, A. R. Protein and peptides in pictures: Imaging with MALDI mass spectrometry. Proteomics. 8 (18) 3785-3800 (2008)

(77) Chaurand, P.; Norris, J. L.; Cornett, D. S.; Mobley, J. A.; Caprioli, R. M. New Developments in Profiling and Imaging of Proteins from Tissue Sections by MALDI Mass Spectrometry. J. Proteome Res. 5 (11) 2889-2900 (2006)

(78) Aerni, H.-R.; Cornett, D. S.; Caprioli, R. M. Automated Acoustic Matrix Deposition for MALDI Sample Preparation. Anal. Chem. 78 (3) 827-834 (2006)

(79) Seeley, E. H.; Oppenheimer, S. R.; Mi, D.; Chaurand, P.; Caprioli, R. M. Enhancement of protein sensitivity for MALDI imaging mass spectrometry after chemical treatment of tissue sections. J. Am. Soc. Mass Spectrom. 19 (8) 1069-1077 (2008)

(80) Angel, P. M.; Spraggins, J. M.; Baldwin, H. S.; Caprioli, R. Enhanced Sensitivity for High Spatial Resolution Lipid Analysis by Negative Ion Mode Matrix Assisted Laser Desorption Ionization Imaging Mass Spectrometry. Anal. Chem. 84 (3) 1557-1564 (2012)

(81) Wang, H. Y.; Liu, C. B.; Wu, H. W. A simple desalting method for direct MALDI mass spectrometry profiling of tissue lipids. J. Lipid Res. 52, 840-849 (2011)

(82) Wang, H. Y.; Wu, H. W.; Tsai, P. J.; Liu, C. B. MALDI-mass spectrometry imaging of desalted rat brain sections reveals ischemia-mediated changes of lipids. Anal. Bioanal. Chem. 404 (1) 113-124 (2012)

(83) Zhang, Y.; Wang, J.; Liu, J.; Han, J.; Xiong, S.; Yong, W.; Zhao, Z. Combination of ESI and MALDI Mass Spectrometry for Qualitative, Semi-Quantitative and in Situ Analysis of Gangliosides in Brain. Sci. Rep. 6 (1), 25289 (2016) 
(84) Norton, W. T.; Poduslo, S. E. Myelination in Rat Brain: Changes in Myelin Composition During Brain Maturation. J. Neurochem. 21 (4), 759-773 (1973)

(85) Whitehead, S. N.; Chan, K. H. N.; Gangaraju, S.; Slinn, J.; Li, J.; Hou, S. T. Imaging Mass Spectrometry Detection of Gangliosides Species in the Mouse Brain Following Transient Focal Cerebral Ischemia and Long-Term Recovery. PLoS ONE. 6 (6) (2011)

(86) Tettamanti, G.; Bonali, F.; Marchesini, S.; Zambotti, V. A New Procedure for the Extraction, Purification and Fractionation of Brain Gangliosides. Biochim. Biophys. Acta. 296 (1), 160-170 (1973)

(87) Caughlin, S.; Hepburn, J. D.; Park, D. H.; Jurcic, K.; Yeung, K. K.; Cechetto, D. F.; Whitehead, S. N. Increased Expression of Simple Ganglioside Species GM2 and GM3 Detected by MALDI Imaging Mass Spectrometry in a Combined Rat Model of A $\beta$ Toxicity and Stroke. 1-17 (2015)

(88) Posse de Chaves, E.; Sipione, S. Sphingolipids and Gangliosides of the Nervous System in Membrane Function and Dysfunction. FEBS Lett. 584 (9), 1748-1759 (2010)

(89) Prokazova, N. V; Samovilova, N. N.; Gracheva, E. V; Golovanova, N. K. Ganglioside GM3 and Its Biological Functions. Biochemistry. (Mosc). 74 (3), 235-249 (2009)

(90) McFarland, M. A.; Marshall, A. G.; Hendrickson, C. L.; Nilsson, C. L.; Fredman, P.; Månsson, J.-E. Structural Characterization of the GM1 Ganglioside by Infrared Multiphoton Dissociation, Electron Capture Dissociation, and Electron Detachment Dissociation Electrospray Ionization FT-ICR MS/MS. J. Am. Soc. Mass Spectrom. 16 (5), 752-762 (2005) 
(91) Ledeen, R. W.; Wu, G. The Multi-Tasked Life of GM1 Ganglioside, a True Factotum of Nature. Trends Biochem. Sci. 40 (7), 407-418 (2015)

(92) Gónzalez de San Román, E.; Manuel, I.; Giralt, M. T.; Ferrer, I.; Rodríguez-Puertas, R. Imaging Mass Spectrometry (IMS) of Cortical Lipids from Preclinical to Severe Stages of Alzheimer's Disease. Biochim. Biophys. Acta - Biomembr. 1859 (9), 1604$1614(2017)$

(93) Kakuda, N.; Miyasaka, T.; Iwasaki, N.; Nirasawa, T.; Wada-Kakuda, S.; TakahashiFujigasaki, J.; Murayama, S.; Ihara, Y.; Ikegawa, M. Distinct Deposition of Amyloid$\beta$ Species in Brains with Alzheimer's Disease Pathology Visualized with MALDI Imaging Mass Spectrometry. Acta Neuropathol. Commun. 5 (1), 73 (2017)

(94) Schneider, J. S.; Sendek, S.; Daskalakis, C.; Cambi, F. GM1 Ganglioside in Parkinson’s Disease: Results of a Five Year Open Study. J. Neuro. Sci. 292, 45-51 (2010)

(95) Maglione, V.; Marchi, P.; Di Pardo, A.; Lingrell, S.; Horkey, M.; Tidmarsh, E.; Sipione, S. Neurobiology of Disease Impaired Ganglioside Metabolism in Huntington's Disease and Neuroprotective Role of GM1. J. Neurosci. 30 (11), 4072$4080(2010)$

(96) Di Pardo, A.; Maglione, V.; Alpaugh, M.; Horkey, M.; Atwal, R. S.; Sassone, J.; Ciammola, A.; Steffan, J. S.; Fouad, K.; Truant, R.; et al. Ganglioside GM1 Induces Phosphorylation of Mutant Huntingtin and Restores Normal Motor Behavior in Huntington Disease Mice. PNAS. 109 (9), 3528-3533 (2012)

(97) Sandhoff, K; Kolter, T. Biosynthesis and degradation of mammalian glycosphingolipids. Philos Trans R Soc Lond B Biol Sci. 358 (1433), 847-861 (2003)

(98) Kolter, T. Ganglioside Biochemistry. ISRN Biochem. (2012) 
(99) Paxinos, G.; Watson, C. (2006) The rat brain in stereotaxic coordinates: hard cover edition. Accessed online via Elsevier

(100) Mai, J. K.; Majtanik, M; Paxinos, G. (2016) Atlas of the Human Brain. Retreived from http://Books.google.com

(101) Heeren, R. M.; Smith, D. F.; Stauber, J.; Kukrer-Kaletas, B.; Macaleese, L. Imaging mass spectrometry: hype or hope? J. Am. Soc. Mass Spectrom. 20, 1006-1014.(2009)

(102) Ivleva, V. B.; Elkin, Y. N.; Budnik, B. A.; Moyer, S. C.; O’connor, P. B.; Costello, C. E. Coupling thin-layer chromatography with vibrational cooling matrix-assisted laser desorption/ionization Fourier transform mass spectrometry for the analysis of ganglioside mixtures. Anal. Chem. 76, 6484-6491 (2004) 


\section{Curriculum Vitae}

\section{Education}

\section{Bachelor of Science, Honors Specialization in Chemistry, Minor in Biology}

September 2013-April 2017

The University of Western Ontario (UWO), London, ON

Relevant Courses: Undergraduate Research Project, Analytical Chemistry, Inorganic Chemistry, Organic Chemistry, Environmental Biology

\section{Enrollment in the Master of Science program for Chemistry}

September 2017-present

The University of Western Ontario (UWO), London, ON

Relevant Courses: Biophysical Chemistry, Integrative Neuroscience

\section{$\underline{\text { TA Experience }}$}

Chemistry 2213A/2223B

- Supervised and assisted undergraduate students as they performed various laboratory techniques in organic chemistry labs

- Evaluated students understanding of laboratory techniques and safety procedures throughout laboratory experiments

\section{$\underline{\text { Publications }}$}

- Co-author

Caughlin S.; Maheshwari S.; Agca Y.; Agca C.; Harris A.J.; Jurcic K.; Yeung K.K.; Cechetto D.F.; Whitehead S.N. Membrane-lipid homeostasis in a prodromal rat model of Alzheimer's disease: Characteristic profiles in ganglioside distributions during aging detected using MALDI imaging mass spectrometry. Biochim Biophys Acta. 2018, 1862 (6), 1327-1338

- Manuscript currently under review at the Journal of the American Society for Mass Spectrometry 
Enhancement of Ganglioside Signal in MALDI MS Imaging of Formalin Fixed Human Brain Tissue Utilizing an Ammonium Formate Wash 